\title{
Creep-fatigue endurance of a superheater tube plate under non- isothermal loading and multi-dwell condition
}

\author{
Nak-Kyun Cho ${ }^{1}$, Run-Zi Wang ${ }^{2}$, Zhiyuan $\mathrm{Ma}^{1}$, Haofeng Chen ${ }^{1,2, *}$, Fu-Zhen Xuan ${ }^{2}$ \\ ${ }^{1}$ Department of Mechanical and Aerospace Engineering, University of Strathclyde Glasgow, G1 1XJ, United \\ Kingdom \\ ${ }^{2}$ Key Laboratory of Pressure Systems and Safety, Ministry of Education, East China University of Science and \\ Technology, Shanghai 200237, P.R.China
}

\begin{abstract}
Raising the operating temperature to increase electricity production in the nuclear power industry is a practical solution in the aspect of efficiency and emissions reduction. However, regarding structural integrity, such high temperature has a significant impact on the life of nuclear power plant components. The superheater tube plate is one of the most critical parts under exposures of very high temperature in the boiler system of the power plant. This study investigates creep-cyclic plasticity behaviour of a superheater outlet tube plate under extremely sophisticated thermo-mechanical loading and evaluates creep-fatigue damage endurance, using the modified LMM eDSCA. Temperature-dependent material properties are employed to calculate more practicable structural behaviour and lifetime prediction. The results clearly present the criticality of the effects of non-isothermal loading and multiple dwells on the structural integrity of the tube plate. Also, this study clarifies critical factors that cause dominant damage to the tube plate by providing total damages using various damage assessment models, of which results show the trend of the conservativeness of each damage assessment model, compared to experiment result.
\end{abstract}

Keywords: Superheater, Non-isothermal, Multi-dwell, Creep-cyclic plasticity, Creep-fatigue damage

\section{Introduction}

With decades of development, the steam power plants have become the primary source of electricity throughout the world. They typically use steam as the working fluid and operate on the Rankine Cycle [1]. As a crucial part of a steam power plant, a traditional and standard shell-and-tube heat exchanging equipment, the superheater has been broadly employed in oil and energy industries [2]. The superheaters often work together with reheaters to increase the saturated steam temperature and make the electricity generation process more efficient. As typical single-phase heat exchangers, they operate the steam inside inner pipes and allow the flue gas outside to heat up the steam, in the form of cross-flow [3]. They are relatively simple and inexpensive to produce and maintain, also being adaptive and reliable to 
withstand working conditions of high temperature and pressure. Among the numerous components of a superheater, tube plates are one of the most critical parts which are attached to the tubes and shell simultaneously. Extremely sophisticated loading conditions can often be detected in a tube plate comprising both complex thermal and mechanical loadings, which may additionally induce creep and fatigue damage.

Many researchers have addressed various approaches to assess creep and fatigue behaviour for engineering components within the steam power plant system, including casings [4, 5], rotors [6] and bolts [7], but many other researches doing creep-fatigue assessment are limited within the scope of material. On the other side, in terms of the scope of structure, the overall structural response can vary significantly if single or multiple creep dwell is considered under a cyclic loading condition [8]. The most crucial feature of cyclic loading with creep is the interaction between cyclic plasticity and creep, which may cause creep ratchetting. Creep ratchetting can be classified as "cyclically enhanced creep" and "creep enhanced plasticity". "Cyclically enhanced creep" is a structural behaviour, in which creep is mainly due to the accumulation of creep strain and long dwell time. "Creep enhanced plasticity" is a precautious structural behaviour where the non-closed hysteresis loop is caused by large creep stress relaxation which creates greater plastic strain accumulation upon unloading. Besides, for components under non-isothermal conditions, the stress relaxation behaviour can be even more complex, which can have a great effect on the evaluation of creep-fatigue damage $[9,10]$.

There are two ways to conduct creep-fatigue assessment in the field of industry: rule-based and analysisbased. Rule-based methods widely adopted by UK's R5 integrity assessment procedure [11] and ASME Boiler and Pressure Vessel Code (NH) [12] are usually considered to be over-conservative and inaccurate. Meanwhile, the finite element (FE) analysis-based method has been developed and improved greatly in the past decade, especially for direct methods that can balance between timeefficiency and accuracy compared to the time-consuming step by step analysis. A general conception of these direct methods is to solve a series of linear problems to evaluate the stress and inelastic strain history based on the linear moduli that vary in both space and time [13]. In recent years, a robust framework known as the Linear Matching Method Framework (LMMF) has been developed to conduct a full structural behaviour assessment. The LMMF integrates several modules, including the elastic and plastic shakedown analysis modules using the original linear matching method (LMM) algorithms [14, 15], the creep rupture assessment module using the extended LMM algorithm [16], the low cycle fatigue (LCF) assessment module using the direct steady cycle analysis (DSCA) method [17], and the creepfatigue interaction assessment module using the extended direct steady cycle analysis (eDSCA) [18].

However, since the LMM eDSCA subroutine can only consider isothermal creep parameters and one dwell period in a load cycle, there is some limitation for the LMM eDSCA to solve more complex 
engineering problems such as structures in non-isothermal condition or multi-dwell creep behaviour within a loading cycle. Besides, numerical procedures implemented in the LMM eDSCA are not able to predict creep stress relaxation history over dwell time. Therefore, the LMM eDSCA was only able to compute the creep damage with an average creep stress value, providing slightly conservative life prediction. Hence the LMM eDSCA is further modified to overcome these limitations, and the detailed update will be described in Section 3 .

In this paper, with the assistance of the modified LMM eDSCA, the effects of the non-isothermal loading on the cyclic creep behaviour and the creep-fatigue life of tube plate under multi-dwell periods are thoroughly investigated. The real geometry data of the forged superheater outlet tube plate and a practical loading condition with six months of operation period are considered. By applying the temperature dependent material parameters taken from experimental data, it obtains the trustworthy structural response under cyclic creep effects and creep-fatigue life of the tube plate. Various methods are used for creep-fatigue damage evaluation of the tube plate. For creep damage evaluation, Time Fraction rule (TF), Ductility Exhaustion method (DE), and Strain Energy Ductility Exhaustion method (SEDE) are employed. For fatigue damage evaluation, the Modified Universal Slope Method (MUSM) and Designed Fatigue Curve provided in ASME NH are considered. For total damage evaluation, the Linear Damage Summation (LDS) method and the Unified Creep-Fatigue equation are used. In consideration of the multiaxial stress state, two types of multiaxial ductility factor (MDF) are employed for the damage evaluation.

This paper has the following structure. Section 2 describes the overall investigation procedures and Section 3 provides details of the numerical methodology. Section 4 presents problem descriptions and relevant modelling parameters, where Section 4.1 describes the finite element model, boundary conditions and loading waveforms of the tube plate structures, and Section 4.2 presents material properties and relevant parameters employed for predicting creep-cyclic plasticity behaviour and creepfatigue damage models. Section 5 demonstrates the performance of the extended LMM eDSCA with numerical results and provides comprehensive discussions on the creep-fatigue interaction of the tube plate. In detail, Section 5.1 focuses on cyclic creep-plasticity behaviour of the tube plate and presents the complex structural response clearly with hysteresis stress-strain loops. Section 5.2 deals with the creep-fatigue damage life of the tube plate based on the damage models mentioned earlier. Finally, Section 6 concludes with critical remarks and findings.

\section{Investigation Procedures}


A flowchart is firstly proposed to exhibit the logic of the numerical investigation in this work in Figure 1.

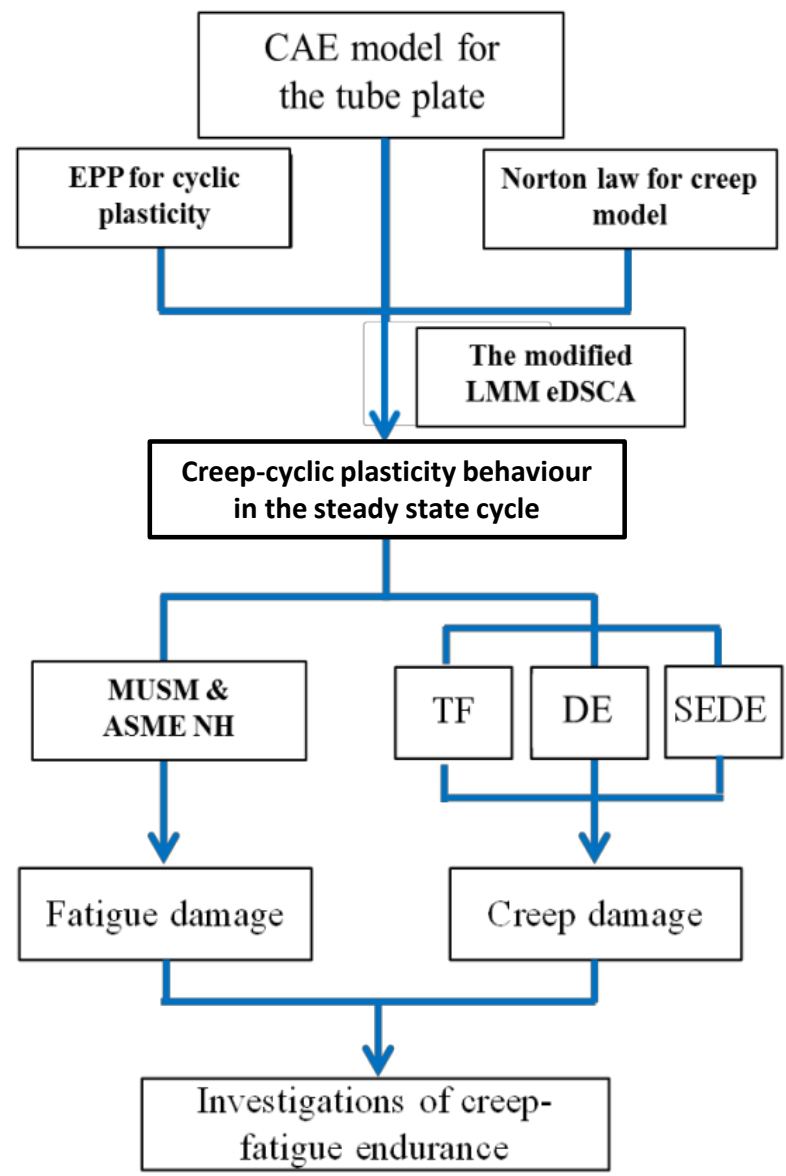

Figure 1 A proposed flow chart for the study of the tube plate through the modified LMM eDSCA method.

The numerical procedures of the modified LMMF with the combinations of a CAE model, the elasticperfectly plastic (EPP) model with temperature dependent yield stresses as well as a temperature dependent creep constitutive equation (Norton law) are used to analyse the cyclic creep and plasticity behaviours of the tube plate in the steady-state cycle. After that, the Modified Universal Slope Method (MUSM) and the Design Fatigue Curve provided in ASME NH are used to evaluate fatigue damage and the Time fraction (TF), the Ductility Exhaustion model (DE) and the Strain Energy Density Exhaustion model (SEDE) are employed to assess creep damage evaluation. Finally, the Linear Damage Summation (LDS) method and the unified creep-fatigue equation are used to evaluate the total damage evaluation. The damage endurance evaluated demonstrates a trend of conservativeness of each evaluation method comparing to experimental data.

\section{Numerical Procedures}


The original numerical procedures of the LMM eDSCA can be found from [18]. In this section, it introduces the modified numerical procedures briefly. Three modifications have been made for calculating the creep strain and flow stress more practically by achieving following three improvements.

The first improvement is to implement non-isothermal creep properties into cyclic creep and plastic analysis. The second improvement is to calculate instantaneous dwell stress, principal stresses and mean or hydrostatic stresses at user-defined dwell time increment within dwell period, which allows more accurate prediction of creep-fatigue damage life. The final improvement is to implement the effects of multi-dwells on calculations of the creep strain and flow stress.

For creep strain calculations within a dwell period, the original LMM eDSCA adopts a time hardening power law equation,

$$
\dot{\bar{\varepsilon}}^{c}=A \cdot \sigma^{n} \cdot t^{m}
$$

where $\dot{\bar{\varepsilon}}^{c}$ denotes creep strain rate; $A\left[M P a^{-n}\right], n$, and $m$ are the creep material constants; $t$ is dwell time in hour.

In order to implement the non-isothermal effects, the creep constant $A$ in Eq.(1) is defined for the variation of the temperature by adopting Arrhenius law,

$$
A=A^{*} \exp \left(-Q_{\text {eng }} / R_{\text {gas }} T\right)
$$

where $Q_{\text {eng }}$ is the activation energy $[\mathrm{kJ} / \mathrm{mol}], R_{\text {gas }}$ is global gas constant $[\mathrm{kJ} / \mathrm{mol} / \mathrm{K}], T$ is the temperature in Kelvin and $A^{*}\left[M P a^{-n} \cdot h^{-m}\right]$ is the frequency factor.

It is assumed that the stress relaxation process follows a linear relation which can be expressed as an elastic follow-up factor $Z$,

$$
\dot{\bar{\varepsilon}}^{c}=-\frac{Z}{\bar{E}} \dot{\bar{\sigma}}
$$


where $\bar{E}$ is the effective Young's modulus which can be defined as $\bar{E}=3 E / 2(1+v), E$ is Young's modulus, $v$ is the Poisson's ratio and $\dot{\bar{\sigma}}=\dot{\bar{\sigma}}\left(\sigma_{i j}\right)$.

We combined the Eq.(1) and Eq.(3) and then integrated the combined equation over the dwell time $\Delta t$ :

$$
\frac{A \bar{E} \Delta t^{m+1}}{Z(m+1)}=\frac{1}{n-1}\left(\frac{1}{\bar{\sigma}_{c}^{n-1}}-\frac{1}{\bar{\sigma}_{s}^{n-1}}\right)
$$

where $\bar{\sigma}_{s}$ is the start of the dwell stress and $\bar{\sigma}_{c}$ is the end of the dwell stress (creep flow stress).

Integrating Eq.(3) over the dwell time $\Delta t$ and then we combined it with Eq.(4) in order to eliminate $Z / \bar{E}$, where $\Delta \bar{\varepsilon}^{c}$ is the effective creep strain increment over the dwell time.

$$
\Delta \bar{\varepsilon}^{c}=\frac{A(n-1) \Delta t^{m+1}\left(\bar{\sigma}_{s}-\bar{\sigma}_{c}\right)}{\left(\bar{\sigma}_{c}^{-n+1}-\bar{\sigma}_{s}^{-n+1}\right)(m+1)}
$$

For predicting the creep stress relaxation history, it is assumed that the resulting dwell stress against a time increment has the following relationship [10] for the arbitrary elastic follow-up $Z$ value as Eq.(3),

$$
\bar{\sigma}_{c, i}=\left\{\bar{\sigma}_{s, i}^{-n+1}+\frac{1}{Z}\left(\frac{n-1}{m+1}\right) B \bar{E} \Delta t_{i}^{m+1}\right\}^{\frac{-1}{n-1}}
$$

where $\bar{\sigma}_{c, i}$ and $\bar{\sigma}_{s, i}$ are the instantaneous end of the dwell stress and the instantaneous start of the dwell stress respectively; $B$ is the creep coefficient for the instantaneous time increment $\Delta t_{i}$ over the dwell time $\Delta t$.

Hence, equations (4) and (5) can be transformed into the following equations (7) and (8) to calculate the instantaneous effective creep strain increment, and the creep strain increment over the dwell period can be calculated as $\Delta \bar{\varepsilon}^{c}=\Delta \bar{\varepsilon}_{\Delta t}^{c}$ : 


$$
\begin{aligned}
& \frac{A \bar{E} \Delta t_{i}^{m+1}}{Z(m+1)}=\frac{1}{n-1}\left(\frac{1}{\bar{\sigma}_{c, i}^{n-1}}-\frac{1}{\bar{\sigma}_{s}^{n-1}}\right) \\
& \Delta \bar{\varepsilon}_{i}^{c}=\frac{A(n-1) \Delta t_{i}^{m+1}\left(\bar{\sigma}_{s}-\bar{\sigma}_{c, i}\right)}{\left(\frac{1}{\bar{\sigma}_{c, i}^{n-1}}-\frac{1}{\bar{\sigma}_{s}^{n-1}}\right)(m+1)}
\end{aligned}
$$

Utilising the dwell stress history, the principal stress history $\left(\Delta \sigma_{1}, \Delta \sigma_{2}\right.$, and $\Delta \sigma_{3}$ ) and the mean stress history $\left(\Delta \sigma_{m}=\frac{\Delta \sigma_{1}+\Delta \sigma_{2}+\Delta \sigma_{3}}{3}\right)$ can be predicted over the dwell time using interpolation techniques, the analysed $\Delta \sigma_{1}$ and $\Delta \sigma_{m}$ are used to calculate a creep damage prediction based on time fraction rule and stress modified exhaustion method allowing for multi-axial ductility factors $[19,20]$. All the mathematical formula shown in Section 4.2 is also implemented in this modified version of eDSCA for the damage calculations.

The creep strain rate $\dot{\bar{\varepsilon}}_{i}^{c}$ at the dwell time increment $\Delta t_{i}$ is calculated from Eq.(7) and Eq.(8).

$$
\dot{\bar{\varepsilon}}_{i}^{c}=\frac{\Delta \bar{\varepsilon}_{i}^{c}(m+1) \bar{\sigma}_{c, i}^{n}}{(n-1)\left(\bar{\sigma}_{s}-\bar{\sigma}_{c, i}\right) \Delta t_{i}}\left(\bar{\sigma}_{c, i}^{-n+1}-\bar{\sigma}_{s}^{-n+1}\right)
$$

Initially, the iterative process starts with estimated $\bar{\sigma}_{s}$ and $\bar{\sigma}_{c, 0}$ values, and the Eq.(8) and Eq.(9) compute new creep flow stress $\bar{\sigma}_{c, i}{ }^{f}$ using Eq.(10) so that the new creep flow stress is used to conform to the linear matching condition.

$$
\bar{\sigma}_{c, i}^{f}=\left(\frac{\dot{\bar{\varepsilon}}_{i}^{c}}{A \Delta t_{i}^{m}}\right)^{\frac{1}{n}}
$$

For the multi-dwell effects, the eDSCA has been modified as the users can input a number of loading instances in the UMAT subroutines as they wish. The enhanced procedure makes the resultant stress and strain from a prior loading instance to become a residual stress field for stress and strain calculations in the next loading instance. 


\section{Problem Description}

\subsection{Finite element model and boundary conditions}

An FE model of the simplified superheater tube plate with the 14 tailpipe configurations is created as shown in Figure 2. Some features on the actual industrial tube plate are not modelled including the steam pipes (thin pipes that penetrate through the bores), pintles (connection components between steam pipes and tube plate on external surface in Figure 2-(b)), internal tailpipes (connection components between steam pipes and tube plate on internal surface in Figure 2-(a)), and sheath tube (a case being welded to tube plate on surface in Figure 2-(d)). The reason is that the stress concentration occurs around the bore surface of the tube plate perforation regardless of the presence of these features. The corners inside the tube plate have been modelled with round fillets albeit that the gouge outside the tube plate for gimbal attachment has been neglected. It is worth mentioning that only nominal dimensions are adopted during the modelling process as no corrosion or erosion is considered. The detailed dimensions are shown in Table 1and Figure 3-(a) and -(b).

(a)

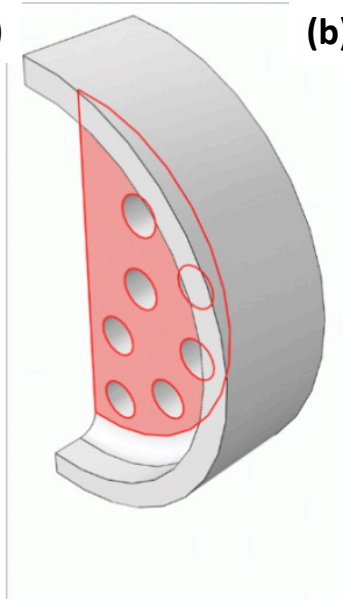

(b)

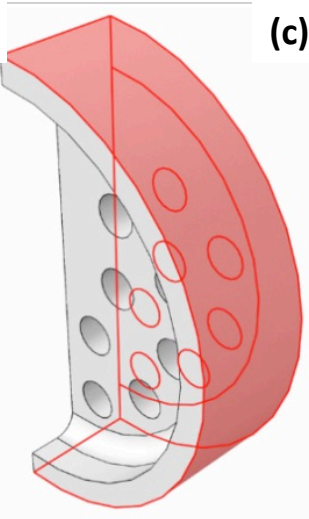

(c)

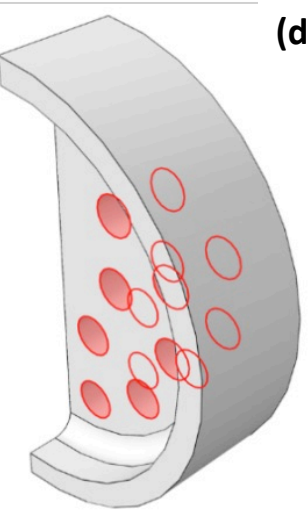

(d)

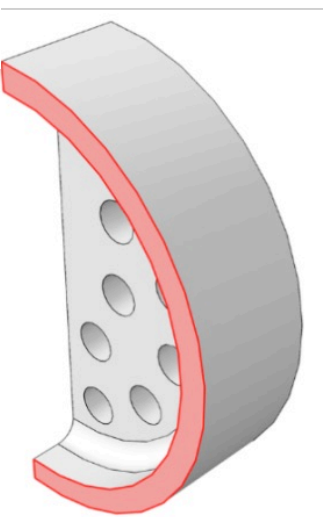

Figure 2 Simplified 3-dimensional tube plate model with certain surfaces selected: (a) internal surface, (b) external surface, (c) tube holes, and (d) sheath tube weld surface.

Half of the whole tube plate is modelled since the structure is symmetric about the y-z plane. The FE model is constructed and meshed using commercial finite element software ABAQUS as shown in Figure 3-(c). The model consists of 15832 quadratic brick elements. For heat transfer analysis and stress analysis, the identical geometry and mesh configurations are used excepting the element type, where DC3D20 for heat transfer analysis and C3D20R for stress analysis respectively. 


\begin{tabular}{lllll}
\hline $\mathbf{T}$ & $\mathbf{t}$ & $\mathbf{D}$ & $\mathbf{d}$ & $\mathbf{a}$ \\
\hline 110 & 60 & 421 & 38.3 & 24 \\
\hline
\end{tabular}

(a)

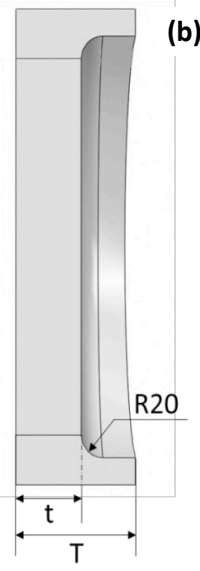

(b)

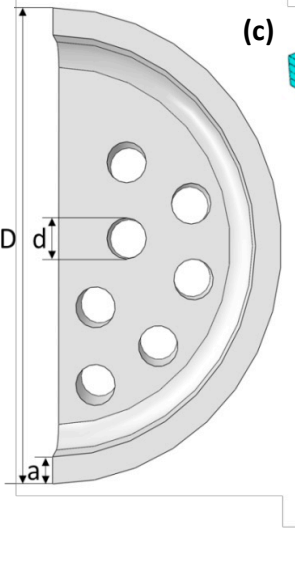

(c)

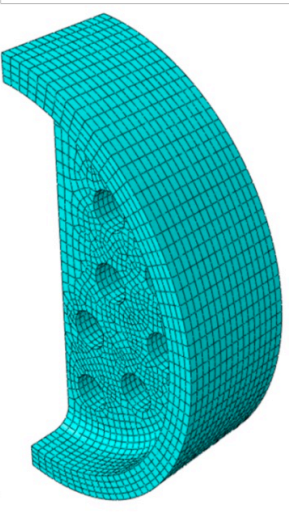

Figure 3 (a) Side view of the tubeplate model, (b) Front view of the tubeplate model, and (c) meshed tube plate.

The loading waveform and boundary condition are assumed based on the actual working condition of a six months super-heater operation. For normal full power reactor transient, the boil gas inlet temperature is $680{ }^{\circ} \mathrm{C}$ and the gas pressure is $4.1 \mathrm{MPa}$, which are applied to the external surfaces in Figure 2 (b) of the tube plate. The steam temperature is $530{ }^{\circ} \mathrm{C}$ and the steam pressure is $16.9 \mathrm{MPa}$, which are applied to the inside surfaces in Figure 2 (c) of the bores of tube plate. With multi-dwell stages in the loading waveform, it considers the thermal and mechanical loads cycle between $100 \%$ of full power loading and 105\% of full power loading, as shown in Figure 4.

No pressures are applied on the internal surfaces in Figure 2 (a) of the tube plate, which operates at atmospheric pressure. The thermal load is simplified by that it applies the temperature directly to the surfaces without considering heat transfer coefficients between the working fluid and solid structure. The reason is not only for simplicity but also for conservatism as the simplified thermal condition has been proved to yield larger thermal stress than the actual working condition. In addition, only the pressure and temperature loading are considered, but the self-weight of the tube plate is neglected since it has an insignificant effect on simulation results. 


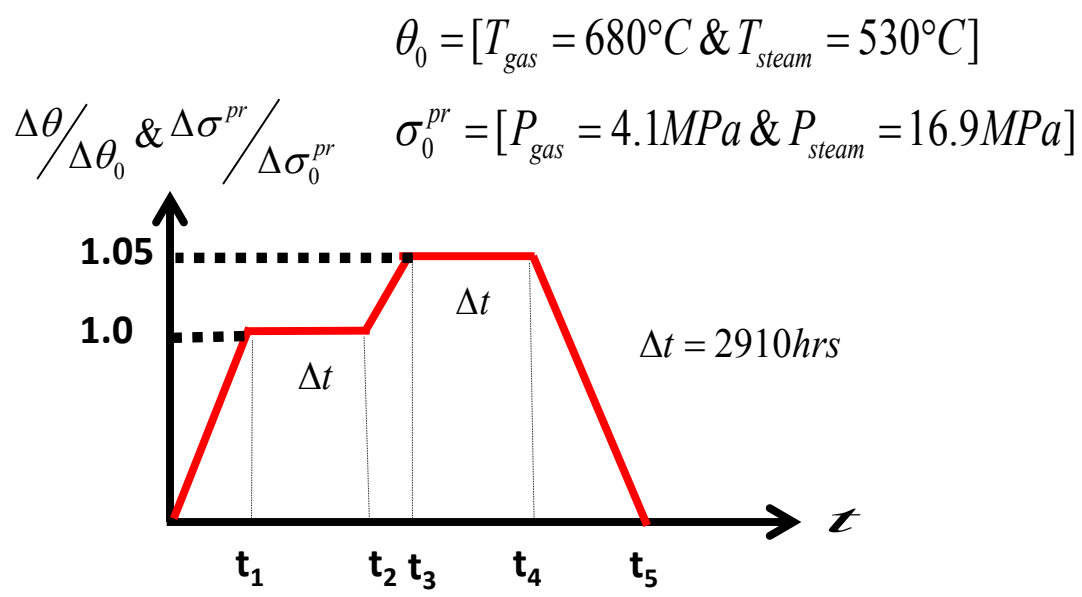

Figure 4 Loading waveform under multi-dwell for six months operations.

A reference point is created with six degrees of freedom fixed at the centre of tube plate, which is also connected to the tube plate - sheath tube weld surface (surface in Figure 2 (d)) by means of kinematic coupling constraint. This constraint has been configured to allow the weld surface to expand only in radial direction. In addition, a symmetry boundary condition about x-direction has been applied to simulate the whole structure with the half model. According to the trial heat transfer assessment, the circumferential distribution of temperature alongside the sheath tube may cause the deformation of the weld surface in both axial and circumferential directions. Thus the existing boundary condition may over-constrain the surface in the circumferential direction. But this over-constraint is acceptable because the stiffness of the tube plate is judged to be much larger than the sheath tube in the case of this deformation mode.

Regarding the deformation in the axial direction, it has confirmed that stress concentration happens within the tube plate body, away from the area affected by the axial temperature variation. Therefore, regarding rationality and simplicity, these influences have been disregarded. Incidentally, in accordance with actual working conditions, there are some constraints and end-pipe loadings generated from tailpipes and steam tubes being also neglected herein because they are quite flexible and are remote from regions of stress concentration.

\subsection{Material properties and modelling parameters}

\section{i) Cyclic plasticity}

Type $316 \mathrm{H}$ stainless steel is often used as a material for the superheater outlet tube plate. The temperature dependent proof stress of $0.2 \%$ are created within a reasonable stress range based on creep rupture stresses of Type 316L stainless steel for 10,000 hours [21]. It is worth to mention that the implemented temperature dependent elastic perfectly plastic model ensures the conservativeness of the results compared to cyclic hardening behaviours. Table 2 shows the temperature-dependent yield 
stresses for the temperature ranges between $20^{\circ} \mathrm{C}$ and $750^{\circ} \mathrm{C}$. The yield stresses unspecified in Table 2 are calculated by extrapolation method implemented in the modified LMM eDSCA.

Table 2 Temperature dependent yield stresses of Type316H stainless steel

\begin{tabular}{cccccccc}
\hline Temp. $\left[{ }^{\circ} \mathrm{C}\right]$ & 20 & 500 & 550 & 600 & 650 & 700 & 750 \\
\hline$\sigma_{y}[\mathrm{MPa}]$ & 205 & 110 & 105 & 100 & 95 & 90 & 85 \\
\hline
\end{tabular}

\section{ii) Creep constitutive model}

Considering that each dwell period is three months, the inelastic deformation of the tube plate due to creep is assumed to follow Norton law which shows the secondary creep regime and the temperature dependent creep parameter $A^{*} \exp \left(\frac{-Q_{\text {eng }}}{R_{\text {gas }} T}\right)$ is applied by using Arrhenius law,

$$
\dot{\bar{\varepsilon}}^{c}=A^{*} \cdot \exp \left(-Q_{\text {eng }} / R_{\text {gas }} T\right) \bar{\sigma}^{n}
$$

where $\dot{\bar{\varepsilon}}^{c}$ is the equivalent creep strain rate, $A^{*}$ is the frequency factor, $Q_{\text {eng }}$ is the activation energy $\left[K J \cdot m o l^{-1}\right], R_{g a s}$ is the gas constant $\left[J \cdot \mathrm{mol}^{-1} \cdot \mathrm{K}^{-1}\right], T$ represents temperature in Kelvin $[K]$ and $n$ is the stress component. The creep parameters are created and adjusted for typical creep deformation behaviours of Type 316 stainless steel based on a literaure [22] and are listed in Table 3.

Table 3 Creep parameters for calculating creep strain.

\begin{tabular}{cccc}
\hline$A^{*}$ & $Q$ & $R$ & $n$ \\
\hline 46333.8 & 330 & 8.314 & 6.1 \\
\hline
\end{tabular}

\section{iii) Creep-fatigue damage models}

The framework of Linear Damage Summation (LDS) divides the creep-fatigue estimation into two parts, namely the fatigue damage and creep damage in the steady-state cycle. The equation of the general creep-fatigue life prediction based on LDS can be expressed as

$$
N_{c f}=\frac{1}{D_{f}+D_{c}}
$$


where $N_{c f}$ is the number of cycles to creep-fatigue failure, $D_{f}$ and $D_{c}$ respectively denote fatigue and creep damage in the steady-state cycle.

As mentioned in Section 2, the Modified Universal Slope Method (MUSM) is used to calculate fatigue damage $d_{f}^{M U S M}$ of Type 316 stainless steel. With consideration of the high temperature operating condition, tensile strength $\sigma_{B}$ of Type 316 stainless steel is replaced with creep rupture stress of 68 $\mathrm{MPa}$ at $700{ }^{\circ} \mathrm{C}$ for 10,000 hours [21] and fatigue ductility $\varepsilon_{f}$ is assumed to be 0.4 which is found to be 0.077 at room temperature. If tensile strength decreases and fatigue ductility increases, the number of cycle to fatigue failure $N_{f}$ shorten, leading to predict more conservative fatigue lifetime than one at room temperature.

$$
\frac{\Delta \varepsilon}{2}=0.623\left(\frac{\sigma_{B}}{\bar{E}}\right)^{0.832} 2 N_{f}^{-0.09}+0.0196 \varepsilon_{f}^{0.155}\left(\frac{\sigma_{B}}{\bar{E}}\right)^{-0.53} 2 N_{f}^{-0.56}
$$

$\mathrm{TF}, \mathrm{DE}$, and SEDE methods are employed to predict creep damage life and compare the prediction capacities. It is known that TF and DE have been widely used in engineering structures and incorporated into ASME NH, RCC-MRx, and R5 procedure respectively. However, some limitations remain in predictions of increased creep damage of Type 316 stainless steel for longer dwell periods.

The multiaxial rupture stress, $\sigma_{R U P}$, and creep rupture time, $t_{f}$, are considered to be the two dominated parameters that have a great impact on creep damage in the steady-state cycle in TF model, which is given by

$$
d_{c}^{T F \cdot \sigma_{R U P}}=\int_{0}^{\Delta t} \frac{d t}{t_{f}\left(\sigma_{R U P}, T\right)}
$$

where $d_{c}^{T F \cdot \sigma_{R U P}}$ is the creep damage in the steady-state cycle by using the TF model. The function of $t_{f}\left(\sigma_{R U P}, T\right)$ can be expressed as the following two equations:

$$
\begin{gathered}
\log t_{f}\left(\sigma_{R U P}, T\right)=k \cdot \sigma_{R U P}{ }^{-\alpha} \\
\sigma_{R U P}=0.133 \times 3 \sigma_{m}+0.867 \bar{\sigma}
\end{gathered}
$$


where $k$ and $\alpha$ are two material constants in the power-law relationship, and $\bar{\sigma}$ is the instant equivalent stress. The magnitudes of $k$ and $\alpha$ at various temperatures between $500{ }^{\circ} \mathrm{C}$ to $750{ }^{\circ} \mathrm{C}$ for the TF model are based on reference [21], as listed in Table 4. The parameters $k$ and $\alpha$ for nonspecified temperatures between $500{ }^{\circ} \mathrm{C}$ and $750{ }^{\circ} \mathrm{C}$ are calculated using the interpolation technique implemented in the modified LMM eDSCA.

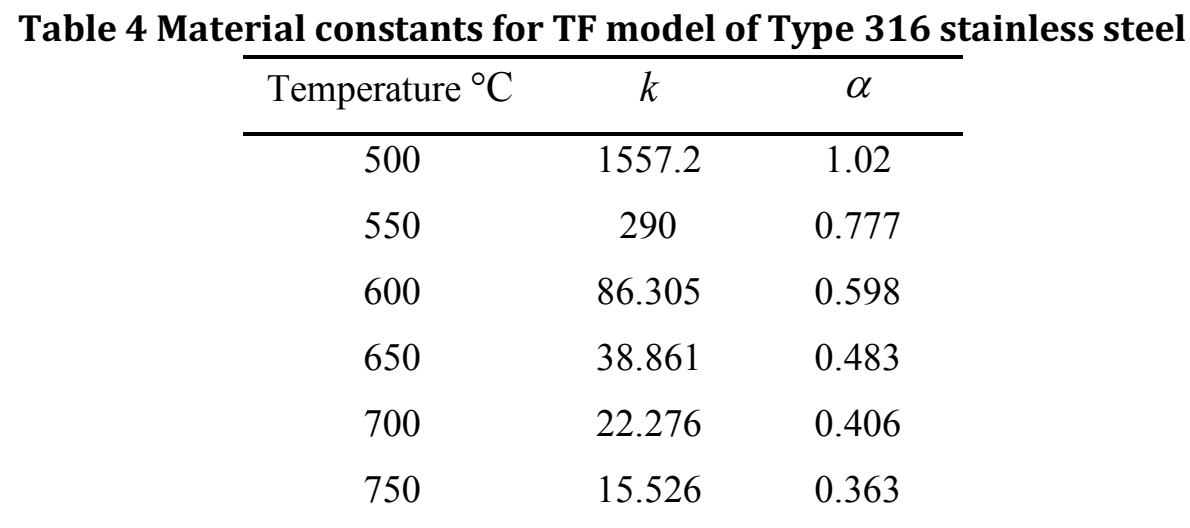

The multiaxial creep damage is calculated on the basis of R5 ductility exhaustion model (DE), where the creep ductility, $\varepsilon_{f}^{c}$, has a function of the creep strain rate $\dot{\bar{\varepsilon}}^{c}$ and temperature. The creep damage in the steady-state cycle with the combinations of DE model and multiaxial ductility factor (MDF), $d_{c}^{D E \cdot M D F}$, can be written as

$$
d_{c}^{D E \cdot M D F}=\int_{0}^{\Delta t} \frac{\dot{\bar{\varepsilon}}^{c}}{\bar{\varepsilon}_{f}^{c}\left(\dot{\bar{\varepsilon}}^{c}, T\right) \cdot M D F} d t
$$

In the uniaxial form, the creep ductility $\varepsilon_{f}^{c}$ can be expressed by:

$$
\varepsilon_{f}^{c}=\min \cdot\left[\varepsilon_{U}, \operatorname{Max} \cdot\left(\varepsilon_{L}, B^{*} \dot{\varepsilon}_{c}^{m^{*}}\right)\right]
$$

where $\varepsilon_{U}$ is the upper shelf at high strain rates; $\varepsilon_{L}$ is the lower shelf at low strain rates; $B^{*}$ and $m^{*}$ are the material parameters. Creep ductility $\bar{\varepsilon}_{f}$ that considers effects of MDF can be represented as Eq. (18): 


$$
\bar{\varepsilon}_{f}^{c}=\varepsilon_{f}^{c}\left(\dot{\bar{\varepsilon}}^{c}, T\right) \cdot M D F=\varepsilon_{f}^{c}\left(\dot{\bar{\varepsilon}}^{c}, T\right) \exp \left[p\left(1-\frac{\sigma_{1}}{\bar{\sigma}}\right)+q\left(\frac{1}{2}-\frac{3 \sigma_{m}}{2 \bar{\sigma}}\right)\right]
$$

where $\sigma_{1}$ and $\sigma_{m}$ are the maximum principal stress, mean or hydrostatic stress respectively; $p=2.38$ and $q=1.04$ are the empirically derived constants for austenitic steels[23]. Parameters for Eq.(17) should consider non-isothermal temperature effects, but limited published data exists. Thus parameters of uniaxial creep ductility of ex-service Type $316 \mathrm{H}$ at $570{ }^{\circ} \mathrm{C}$ and $600{ }^{\circ} \mathrm{C}$ are employed for creep damage evaluation based on DE method. The detailed parameters are listed in Table 5. According to Section 5.1 analysis results, maximum creep deformation occurs near the tube holes, and this region has a temperature range from $530^{\circ} \mathrm{C}$ to $560{ }^{\circ} \mathrm{C}$.

Table 5 Material constants for creep ductility of type 316H stainless steel [24].

\begin{tabular}{cccc}
\hline$\varepsilon_{U}(\%)$ & $B^{*}$ & $m^{*}$ & $\varepsilon_{L}(\%)$ \\
\hline 50 & 1.0496 & 0.3258 & 6.04 \\
\hline
\end{tabular}

Wen et al. [20] proposed the $\mathrm{MDF}_{\mathrm{WEN}}$ as an alternative way of the MDF provided in R5, which can be expressed as:

$$
M D F_{W e n}=\exp \left[\frac{2}{3}\left(\frac{n-0.5}{n+0.5}\right)\right] / \exp \left[2\left(\frac{n-0.5}{n+0.5}\right) \frac{\sigma_{m}}{\bar{\sigma}}\right]
$$

The strain energy density exhaustion model proposed by Wang et al can not only ensure the prediction accuracy, but also consider the mean stress effect during creep-fatigue process [25]. Based on his research achievement, the SEDE model containing $M D F_{W e n}$ is firstly introduced by this research, where the inelastic strain energy density rate, $\dot{w}_{i n}$, and the failure strain energy density, $w_{f}$, are used to evaluate the creep damage:

$$
d_{c}^{S E D E \cdot M D F_{W e n}}=\int_{0}^{\Delta t} \frac{\dot{w}_{i n}}{w_{f}\left(\dot{w}_{i n}, T\right) \cdot M D F_{W e n}} d t
$$

where $d_{c}^{S E D E \cdot M D F_{W e n}}$ is the creep damage in the steady-state cycle by considering SEDE and MDF ${ }_{\text {WEN }}$. Similarly, the function of $w_{f}\left(\dot{w}_{i n}, T\right)$ by considering the Arrhenius law: 


$$
w_{f}=B_{1} \exp \left(\Delta G_{S E D E} / R T\right) \cdot \dot{w}_{i n}^{B_{2}}
$$

where $B_{1}$ and $B_{2}$ are two material constants for the expression of failure strain energy density, and $\Delta G_{S E D E}$ is the activation energy range in the SEDE model. The parameters of SEDE model are fitted to SMDE data of Type 316H stainless steel [24] and listed in Table 6.

Table 6 Material constants for SEDE model of Type 316H stainless steel.

\begin{tabular}{ccc}
$B_{1}$ & $B_{2}$ & $\Delta G_{S E D E}$ \\
\hline 1.795 & 0.16 & 25843 \\
\hline
\end{tabular}

Different from the previous work for pure strain-controlled tests, the complicated structures are always subjected to mixed strain-stress controlled situations for each integration point. In such a case, it has to mention two different cases that describe the elastic follow-up factor during dwell periods, as seen in Figure 5.
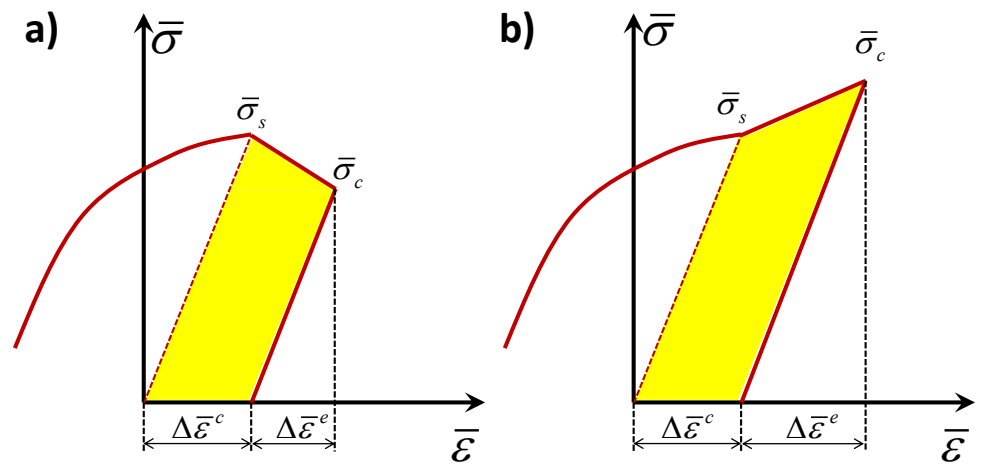

: Stress strain relation

: Driving energy for creep damage

Figure 5 Inelastic strain energy which leads to the creep damage: a) $\bar{\sigma}_{s}>\bar{\sigma}_{c}$ and b)

$$
\bar{\sigma}_{c}>\bar{\sigma}_{s} .
$$

Based on that, the calculations of inelastic strain energy density rate, $w_{i n}$, can be presented as shaded areas defined by:

$$
w_{i n}=\Delta \bar{\varepsilon}^{c} \cdot \bar{\sigma}_{c}+\frac{1}{2}\left\{\Delta \bar{\varepsilon}^{c} \cdot\left(\bar{\sigma}_{s}-\bar{\sigma}_{c}\right)\right\},\left(\bar{\sigma}_{s}>\bar{\sigma}_{c}\right)
$$




$$
w_{i n}=\Delta \bar{\varepsilon}^{c} \cdot \bar{\sigma}_{s}+\frac{1}{2}\left\{\Delta \bar{\varepsilon}^{c} \cdot\left(\bar{\sigma}_{c}-\bar{\sigma}_{s}\right)\right\},\left(\bar{\sigma}_{c}>\bar{\sigma}_{s}\right)
$$

where $\Delta \bar{\varepsilon}^{c}$ is the equivalent creep strain range during one dwell period, and $\bar{\sigma}_{s}$ and $\bar{\sigma}_{c}$ respectively denote the equivalent von-Mises stress at the beginning and end of one dwell period.

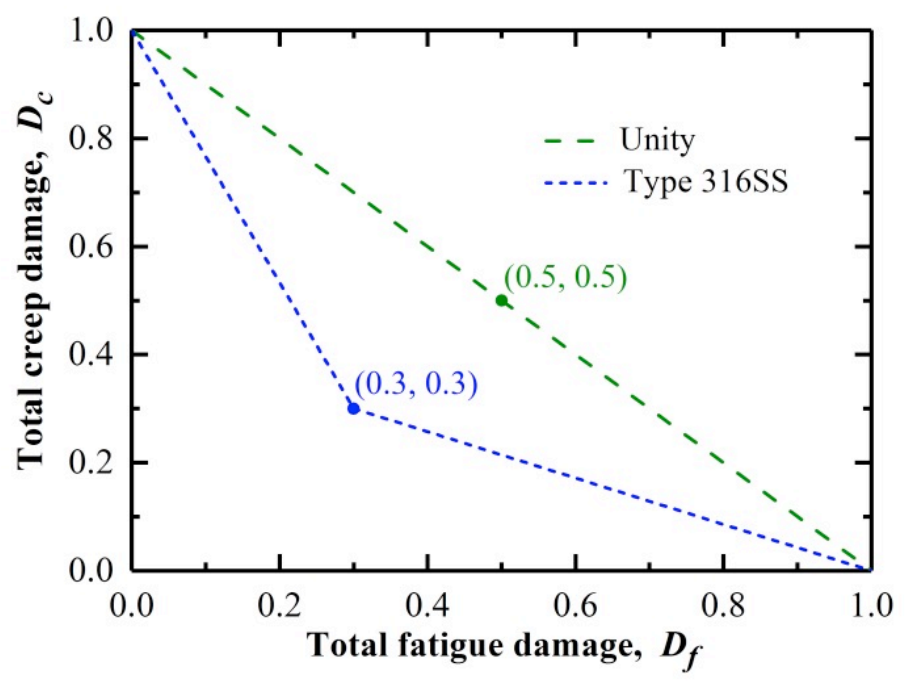

Figure 6 Creep-fatigue damage envelope for Type 316 stainless steel in ASME NH design codes.

After the estimations of fatigue and creep damages, the creep-fatigue interaction diagram provided in ASME NH for type 316 stainless steel can be shown in Figure 6, where the vertical axial is defined as total creep damage, $D_{c}$, and horizontal axial is defined as total fatigue damage, $D_{f}$.

As mentioned in Section 2, the unified creep-fatigue equation in power-law form is used to predict the total damage life $d_{\text {total }}^{\text {unifed }}$ in the steady-state cycle, which can be defined as

$$
\varepsilon_{p}=C_{0}\left[1-c_{1}\left(T-T_{r e f}\right)\right] N_{f-t e m p}^{-\beta_{0}\left[1-b_{1}\left(T-T_{r e f}\right)\right]}
$$

where $\varepsilon_{p}$ is the plastic strain; $C_{0}, c_{1}, \beta_{0}$, and $b_{1}$ are the coefficients; $T_{r e f}$ is the reference temperature of $873 \mathrm{~K}$. It should be mentioned that total strain range $\Delta \bar{\varepsilon}_{\text {total }}$ is used to predict conservative creepfatigue damage life instead of using $\varepsilon_{p}$. Table 7 shows the coefficients of Eq.(23) for fatigue damage evaluation of type 316 stainless steel. 
Table 7 Coefficient of Eq.(23).

\begin{tabular}{ccccc}
\hline Temp. range & $C_{0}$ & $c_{1}$ & $\beta_{0}$ & $b_{1}$ \\
\hline $723 K-873 K$ & 1.997 & 0.002955 & 0.62375 & -0.000309 \\
$873 K-923 K$ & 2.452 & 0.002668 & 0.80713 & 0.00088 \\
\hline
\end{tabular}

\section{Numerical Results and Discussions}

\subsection{Creep-cyclic plasticity behaviour}

The linear elastic analysis is performed for the superheater tube plate subjected to the mechanical load, the thermal load, and the thermo-mechanical load respectively, so that individual loading effects on the tube plate can be understood. The resultant elastic von-Mises stress contours for each loading are illustrated in Figure 7.

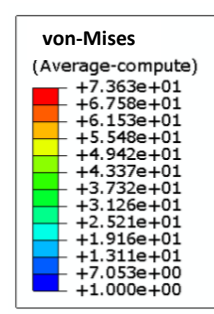

(a)

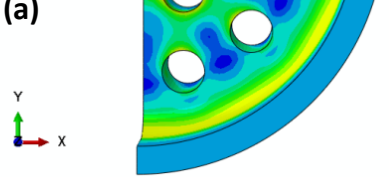

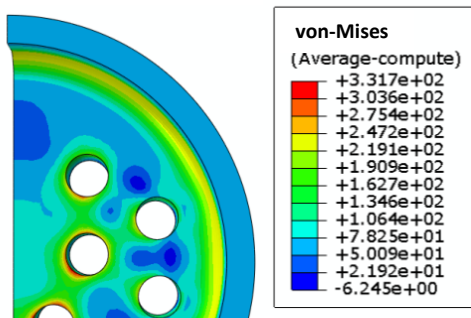

(b)

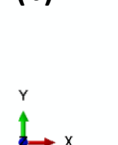

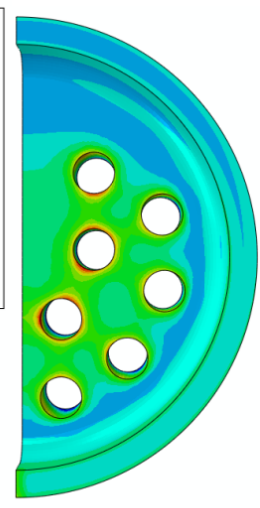
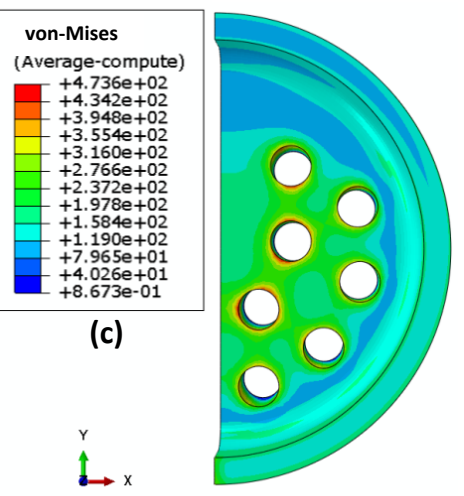

Figure 7 Elastic stress solutions: (a) mechanical load only, (b) thermal load only, and (c) both mechanical and thermal loads.

Figure 7 shows that maximum equivalent stress occurs at holed areas of tube under all three loads. The magnitude of equivalent stress under the thermal load is over four times larger than that under the mechanical load. Figure 7-(c) shows similar equivalent stress distribution contour with the stress distribution under the thermal load only but shows the larger magnitude of the equivalent stress. Hence it can be presumed that the thermal load is the dominant stress component in the thermo-mechanical loading condition, and both the mechanical load and the thermal load produce tensile stresses. It is noteworthy that the maximum magnitude of equivalent stress under the thermo-mechanical loads is more substantial than elastic stress range at tube holed area, hence it is predicted that the tube plate may have significant plastic deformation during loading and unloading load instances. 
The cyclic creep and plastic analysis is performed for the tube plate subjected to the thermo-mechanical load and the multiple dwell periods using the modified LMM eDSCA. Figure 8 exhibits temperature distribution and temperature dependent creep parameters $A^{*} \exp \left(-Q_{\text {eng }} / R_{\text {gas }} T\right)$ over the tube plate at each dwell period. As one of the improvements of the modified LMM eDSCA, the temperature dependent creep parameter effects shown in Figure 8 have been considered in creep-cyclic plasticity behaviour analysed.

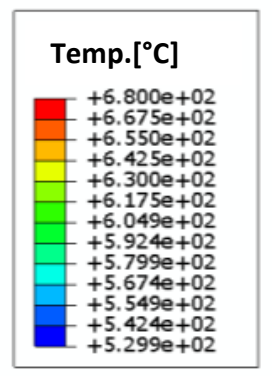

(a)
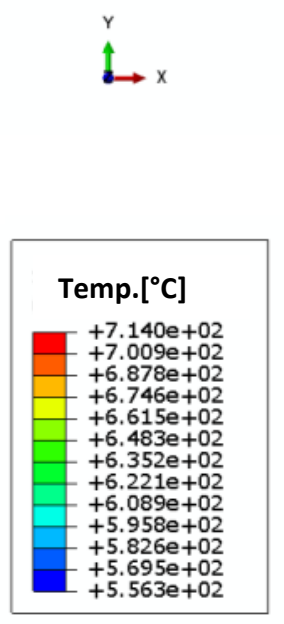

(c)

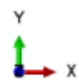

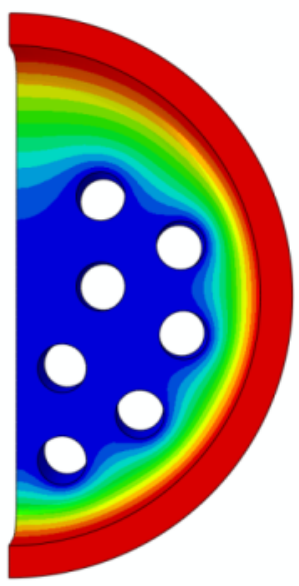
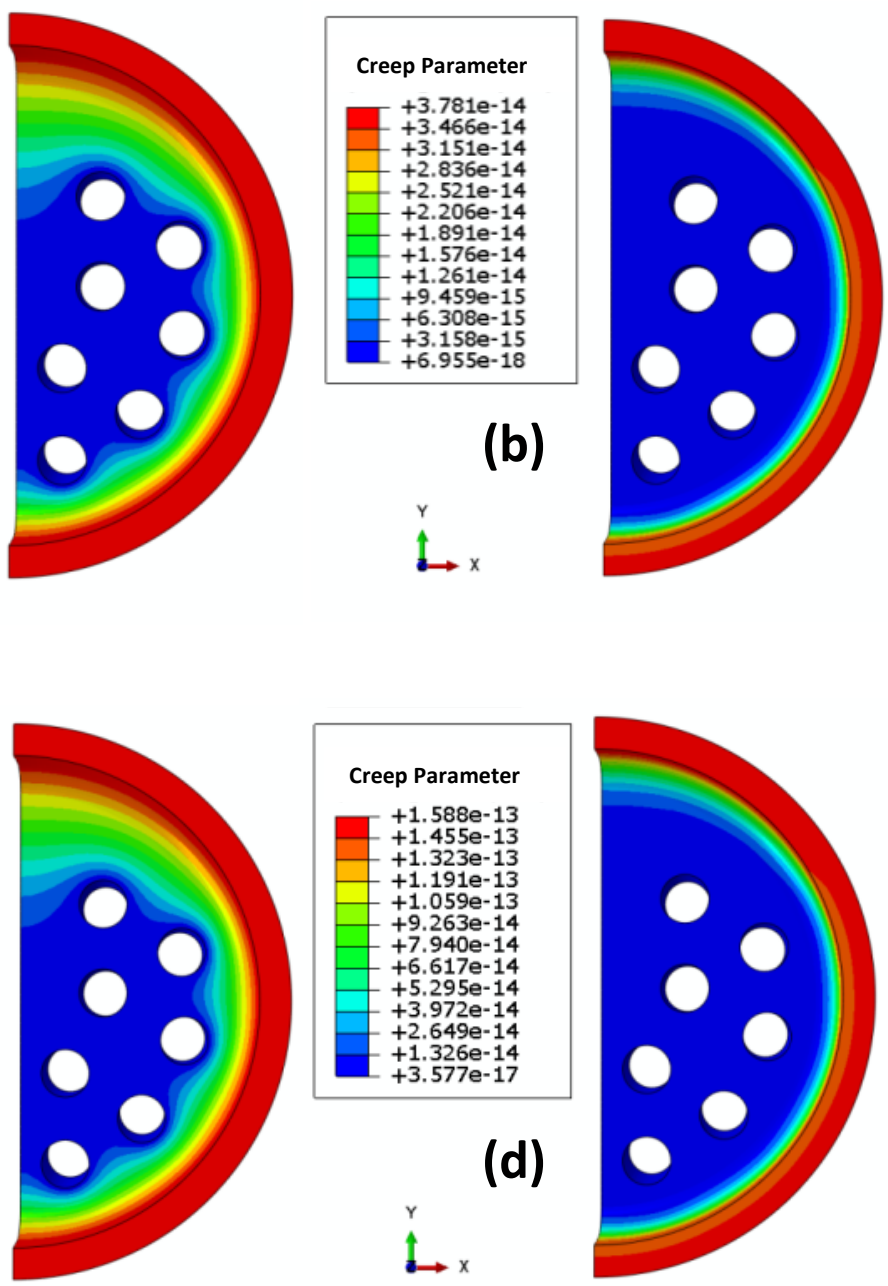

Figure 8 (a) Temperature distribution at the $1^{\text {st }}$ dwell, (b) non-isothermal creep parameters at the $1^{\text {st }}$ dwell, (c) temperature distribution at the ${ }^{\text {nd }}$ dwell, and (d) nonisothermal creep parameters at the $2^{\text {nd }} \mathbf{d w e l l}$.

Figure 9 shows equivalent stress contours at steady cyclic state for each load instance. For all loading instances, the maximum equivalent stress with yielding occurs at the holed area of tube. In the $1^{\text {st }}$ dwell, the loaded stresses relax to approximately half, and the maximum equivalent stresses occur at the inside fillet edges of the tube plate. Due to the $5 \%$ increased loading condition at the $2^{\text {nd }}$ loading, the magnitude of the maximum equivalent stress increases slightly at the inside fillet edges. In the $2^{\text {nd }}$ dwell, the 
imposed stress from the $2^{\text {nd }}$ loading relaxes to around half, but the maximum equivalent stresses occur at the different location, the tube holed area, from the $1^{\text {st }}$ dwell. Finally, Figure 9-(e) shows the residual stress fields of the tube plate at the unloading instance.

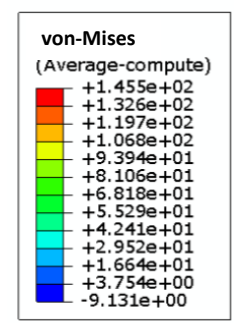

(a)
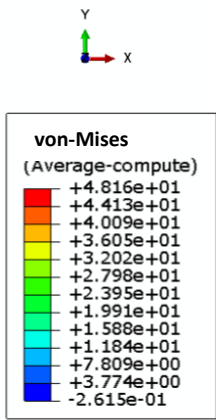

(d)

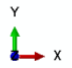

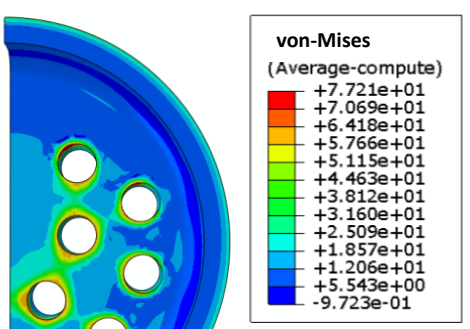

(b)
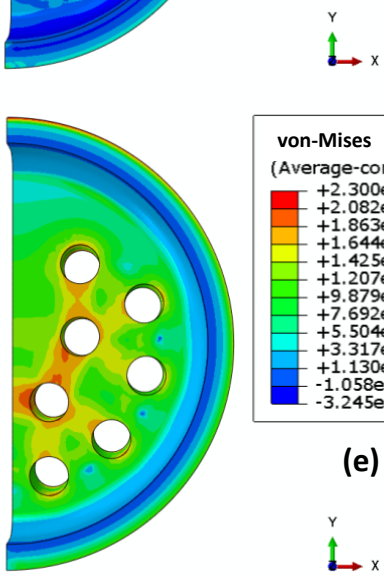
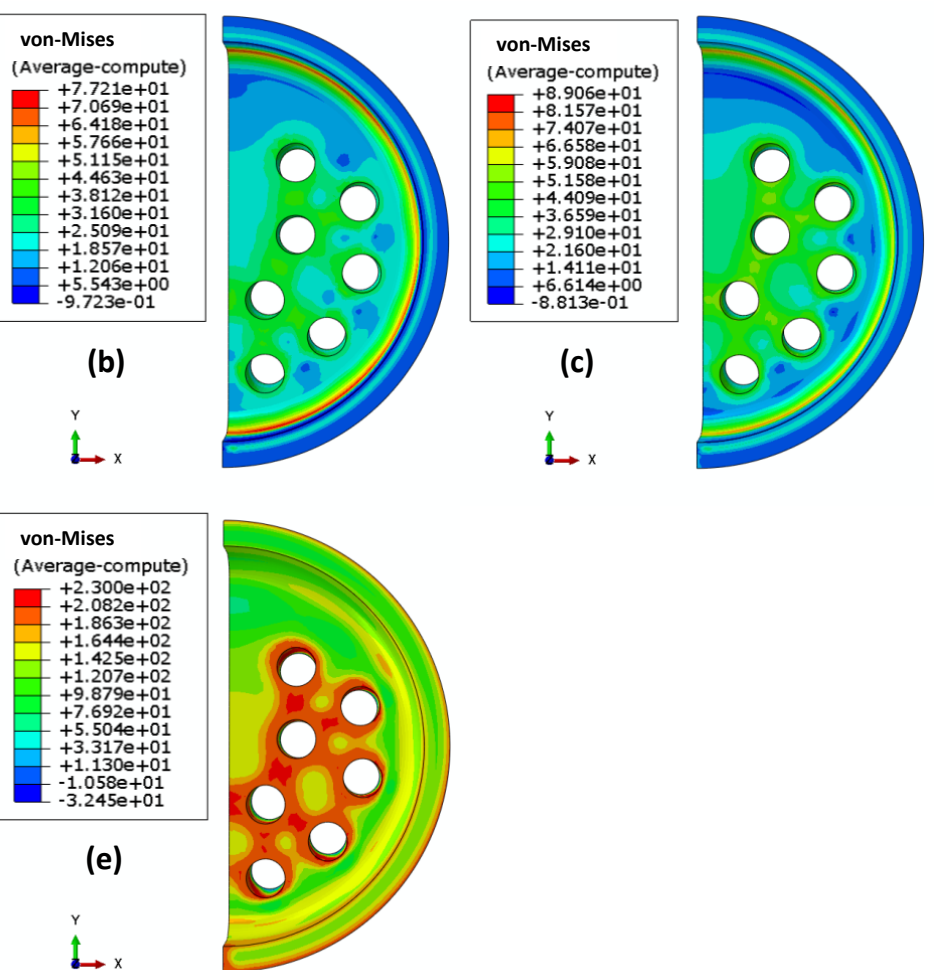

Figure 9 Equivalent stress distribution contours: (a) the $1^{\text {st }}$ loading, (b) the $1^{\text {st }}$ dwell, (c) the $2^{\text {nd }}$ loading, (d) the $2^{\text {nd }}$ dwell, and (e) unloading.

Figure 10 shows maximum effective creep strain increment at each dwell and Figure 11 presents stressstrain hysteresis loops for the concerning locations shown in Figure 10. In the $1^{\text {st }}$ dwell, the maximum creep deformation occurs at the tube holed area in which the element number is 15107 , and in the $2^{\text {nd }}$ dwell, maximum creep deformation occurs at the top of the inside fillet edges in which element number is 2. Ironically maximum creep deformation at each dwell does not occur at locations where maximum equivalent stress occurs. In the monotonic creep test under the isothermal condition, it cannot happen, but it does in the structure level. With shown hysteresis loops in Figure 11, the reasons will be explained. 


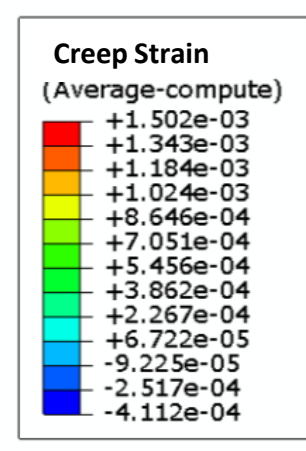

(a)

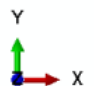

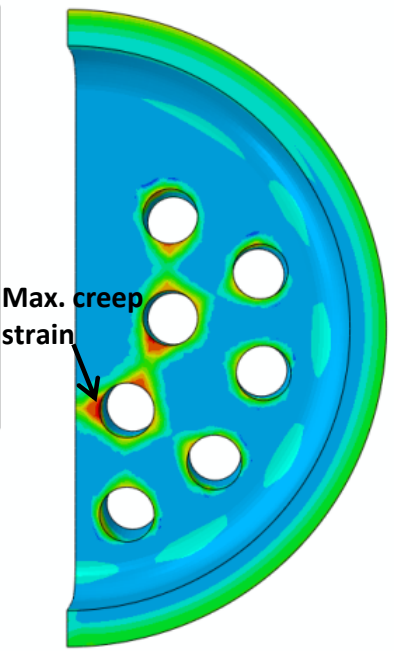

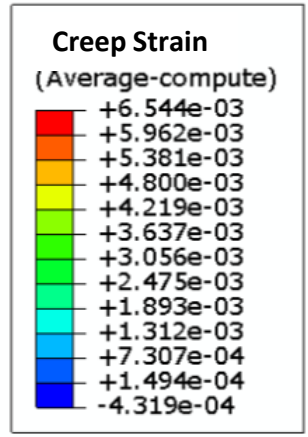

(b)

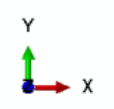

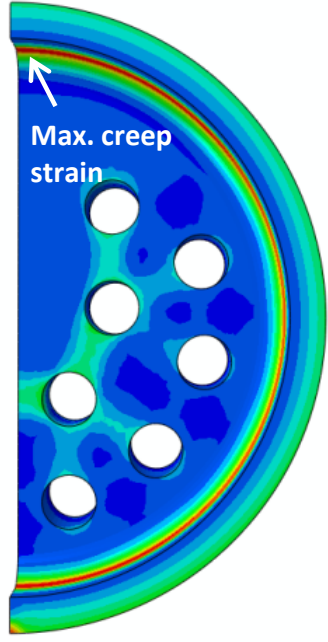

Figure 10 Effective creep strain increment contours at: (a) the $1^{\text {st }}$ dwell (element number: 15107) and (b) the $2^{\text {nd }}$ dwell (element number: 2 ).

For the $1^{\text {st }}$ loading instance, the inside fillet edges produce quite smaller equivalent stress level than tube holed areas; thus an increase of creep stress appears during the $1^{\text {st }}$ dwell. The inside fillet edges have larger creep constants than the tube holed areas due to high temperature, but the small creep stress level at the fillet edges cannot develop significant creep deformation. On the contrary, in the $2^{\text {nd }} d$ dwell, since the start of creep stress level at tube holed areas is similar to the fillet edges, the larger creep constant of the fillet edges develops larger creep deformation than tube holed areas.

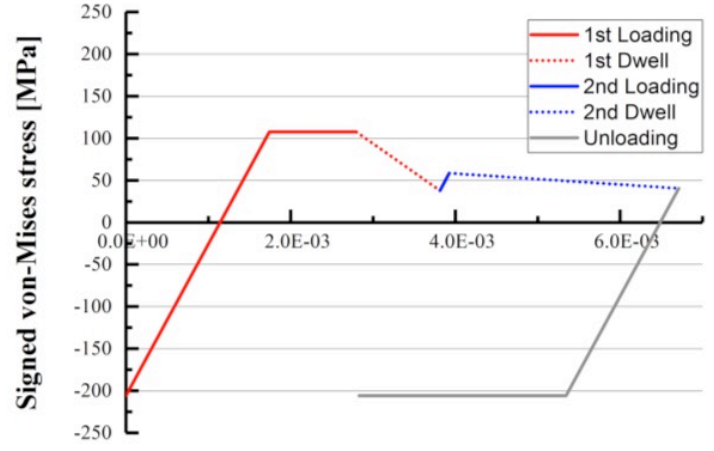

(a)

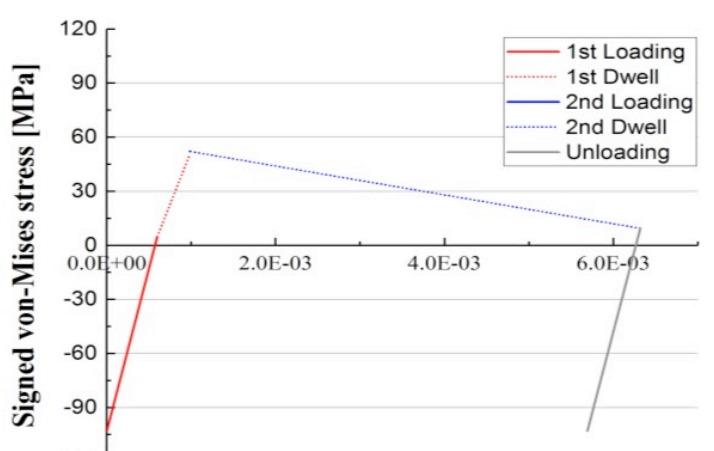

(b)

Figure 11 Saturated stress-strain hysteresis loops for the critical locations: (a) element 15107 and (b) element 2.

For the element 15107, significant creep stress relaxation occurs through both dwell periods, leading to considerable unloading plasticity taking place that reduces ratchetting strain increment. However, owing to no yielding over a cycle occurs at the element 2 , the inside fillet edges causes larger ratchetting 
strain increment than tube holed areas. Both elements 15107 and 2 show creep ratchetting responses in the steady state due to cyclically enhanced creep mechanism.

As one of the improvements in the numerical technique, the modified LMM eDSCA can present stresses and creep strain histories over a dwell period. Table 8 shows the stresses and the creep strain histories for the element 15107 at the $2^{\text {nd }}$ dwell. These relaxation histories in the stresses and the creep strain are essential data to calculate creep-fatigue damage life. In the following section, creep-fatigue damage lives based on commonly used approaches will be evaluated using those relaxation histories.

Table 8 Stresses $[M P a]$ and creep strain histories for the element 15107 at the $2^{\text {nd }} \mathbf{d w e l l}$ : creep stress $\bar{\sigma}_{c}$, effective creep strain $\bar{\varepsilon}^{c}$, principal stresses $\sigma_{1}, \sigma_{2}, \sigma_{3}$ and mean stress $\sigma_{m}$.

\begin{tabular}{ccccccc}
\hline Dwell Time $[h]$ & $\bar{\sigma}_{c}$ & $\bar{\varepsilon}^{c}$ & $\sigma_{1}$ & $\sigma_{2}$ & $\sigma_{3}$ & $\sigma_{m}$ \\
\hline 291 & 53.7 & $7.73 \mathrm{E}-04$ & 23.7 & -0.124 & -16.41 & 2.4 \\
582 & 50.6 & $1.27 \mathrm{E}-03$ & 25.1 & -0.128 & -16.36 & 2.9 \\
873 & 48.3 & $1.63 \mathrm{E}-03$ & 26.2 & -0.131 & -16.33 & 3.2 \\
1164 & 46.6 & $1.91 \mathrm{E}-03$ & 27.0 & -0.134 & -16.31 & 3.5 \\
1455 & 45.2 & $2.14 \mathrm{E}-03$ & 27.7 & -0.136 & -16.29 & 3.8 \\
1746 & 44.0 & $2.34 \mathrm{E}-03$ & 28.3 & -0.137 & -16.27 & 4.0 \\
2037 & 42.9 & $2.50 \mathrm{E}-03$ & 28.8 & -0.139 & -16.26 & 4.1 \\
2328 & 42.0 & $2.64 \mathrm{E}-03$ & 29.2 & -0.14 & -16.24 & 4.3 \\
2619 & 41.2 & $2.77 \mathrm{E}-03$ & 29.5 & -0.141 & -16.23 & 4.4 \\
2910 & 40.5 & $2.88 \mathrm{E}-03$ & 29.9 & -0.142 & -16.22 & 4.5 \\
\hline
\end{tabular}

\subsection{Creep-fatigue damage endurance}

The aim of this section is not to provide a solid conclusion with respect to the selection of damage models. It instead discusses damage lives based on different damage models and utilises the modified LMM eDSCA code for the evaluation of creep-fatigue damages. In this section, TF, DE, and SEDE methods are employed involving multi-axial ductility factors for creep damage calculations. ASME NH and RCC-MRx codes adopt TF method, and instead R5 code employee DE method for creep damage evaluation. The fatigue damage is evaluated by using MUSM shown in Eq.(13) and the Design Fatigue Curve of 316 stainless steel provided in ASME NH.

Figure 12 and Figure 13 present creep damage per cycle in the steady state for each dwell respectively. Calculated creep damage lives based on the three methods are summarised in Table 9. TF method causes maximum creep damage to the inside fillet edge and the outside of the tube plate, where is exposed to the higher temperature, at each dwell respectively, but the concerning areas with considerable creep damage are in compressive stresses. As shown maximum principal stress $\sigma_{1}$ contours in Figure 14, compressive stresses are dominant at high temperature areas for both dwell 
periods. It should be highlighted that the modified LMM eDSCA can produce maximum principal stress history over the dwell period, which can calculate more accurate creep damage under multiaxial stress state.

According to ASME NH [26], creep damage under compressive and multiaxial states of stresses is calculated using Eq.(14). Creep damage life for TF method is calculated with regard to a critical element 5670 which shows the maximum creep damage per cycle within a cycle. TF method is designed to calculate the creep damage from dwell time over creep rupture time at temperature. It is reasonable to see that the maximum creep damage occurs at the higher temperature side in which it has the shorter creep rupture time. Consequently, the tube holed area which has lower temperature than the outside of the tube plate shows smaller creep damage.

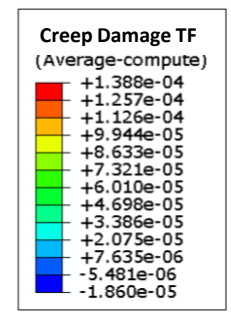

(a)<smiles>[13CH3][13IH]</smiles>
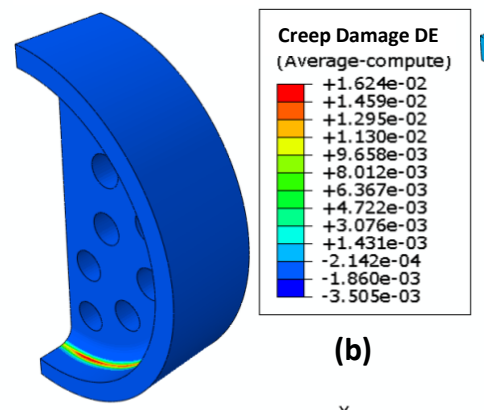

${ }_{z}$
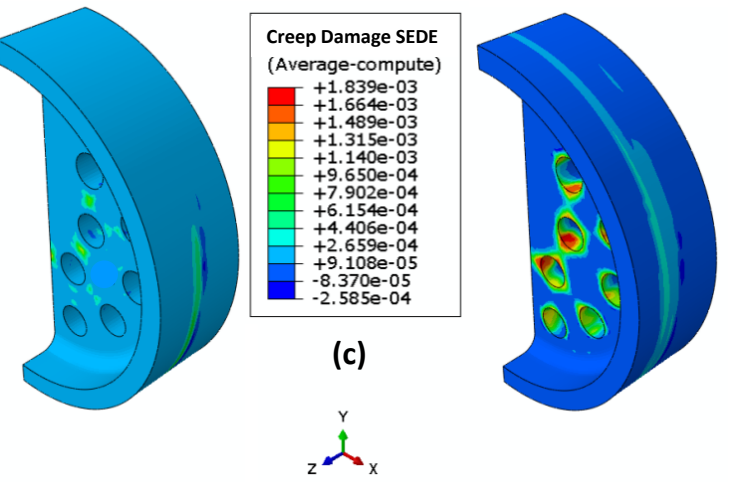

(b) DE model

Figure 12 Creep damage contours at the 1 st $d$ well: (a) TF model with $\sigma$

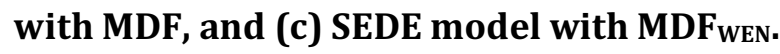

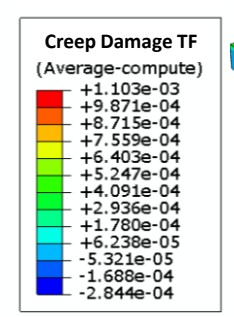

(a)

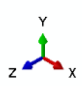

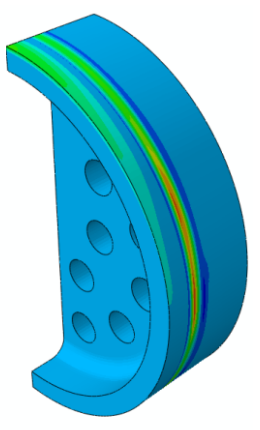

(b)

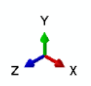

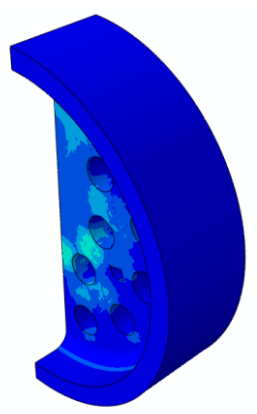
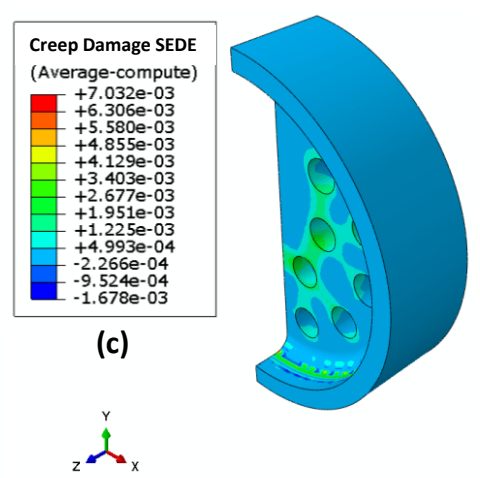

Figure 13 Creep damage contours at the $2^{\text {nd }}$ dwell: (a) TF model with $\sigma_{R U P}$, (b) DE model with MDF, and (c) SEDE model with MDF ${ }_{W E N}$.

It is observed that the maximum creep damage occurs at the element of 15107 for both DE and SEDE models. In reference to Figure 14, the element 15107 is imposed maximum tensile principal stresses 
during both dwell periods. With regard to compressive dwell, the R5 states that the upper shelf uniaxial creep ductility is used to estimate creep damage[11]. Spindler suggested the Stress Modified Ductility Exhaustion method from that creep damage under compressive dwell should be negligible based on creep cavitation mechanism where creep cavities neither nucleates nor grows under compressive stresses[19]. For compressive dwell in both DE and SEDE methods, it is assumed that the creep damage is negligible and the assumption has been implemented into the modified LMM eDSCA. Although the inside fillet edges show the maximum equivalent creep deformation in the 2 nd dwell, they are in compressive stress; thus the element 2 is considered as zero damage as shown in Table 9.

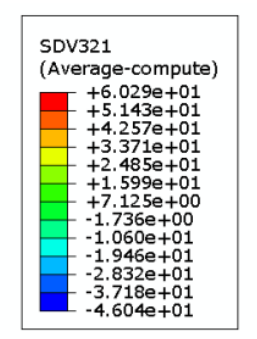

(a)
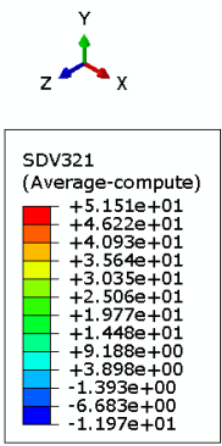

(c)<smiles>[X][CH]C([Y])[Y]</smiles>
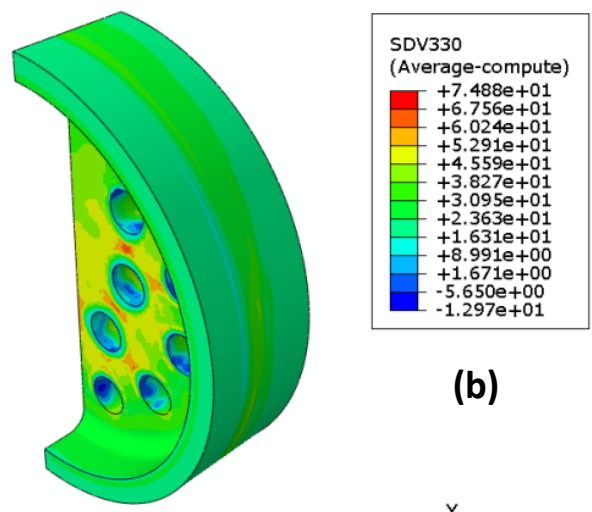

(b)
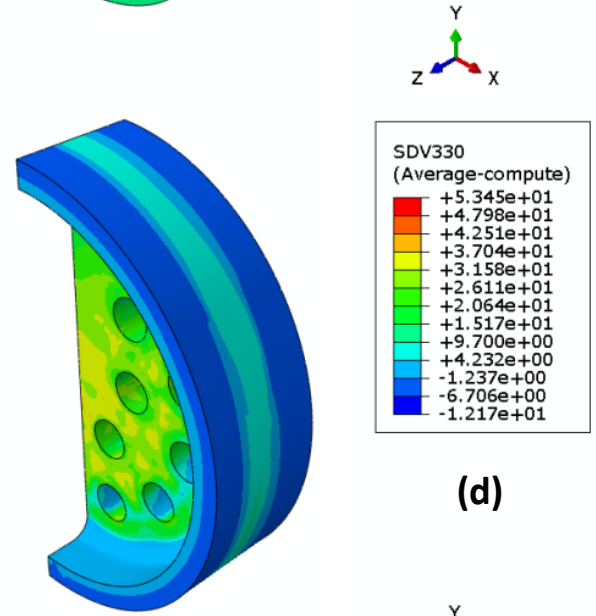
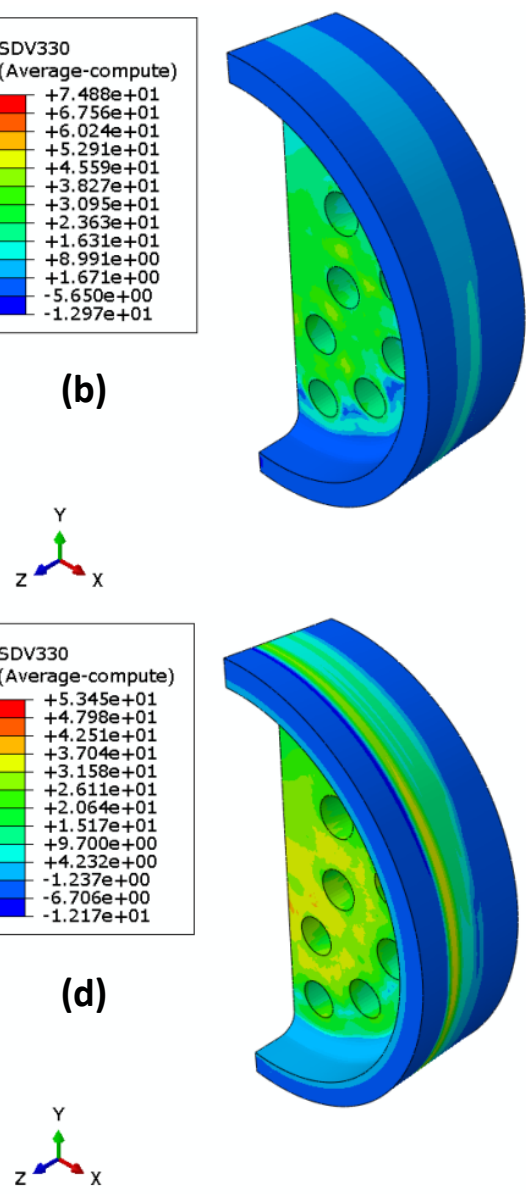

Figure 14 Maximum principal stress contours at dwell periods: (a) start of the $1^{\text {st }} \mathbf{d w e l l}$, (b) end of the $1^{\text {st }}$ dwell, (c) start of the $2^{\text {nd }}$ dwell, and (d) end of the $2^{\text {nd }} \mathbf{d w e l l}$.

It is worth to know that both DE and SEDE methods have an arithmetically identical form, which can convert between SEDE and DE by merely multiplying by or dividing by stress. Thus both DE and SEDE methods show that substantial creep damages occur at the holed areas of tube in which it exhibits large creep deformation as shown in Figure 10. Among the three methods, creep damage per cycle is getting smaller and smaller in the order of DE, SEDE, and TF. 
Figure 15 shows contours of total strain range and fatigue damage per cycle calculated by Eq.(13). The equivalent total strain range and the fatigue damages for the critical locations are listed in Table 9. In the consideration of the sign of the maximum principal stresses, the fillet edges are associated with the compressive deformation, but the tube holed areas induce tensile deformation. Both critical locations have different effects of mean stress on the fatigue life. It is known that the negative stress ratio affects less fatigue damage than the positive stress ratio according to the high-cycle fatigue test of TYPE 316L stainless steel [27]. However, ASME NH gives guidance to evaluate the low cycle fatigue damage using equivalent strain range and provides design fatigue curves for several materials.

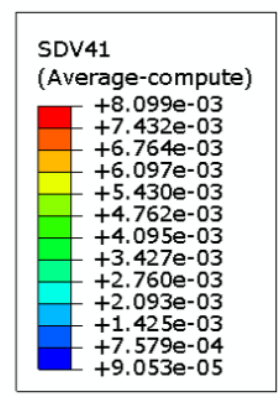

(a)

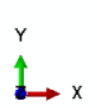

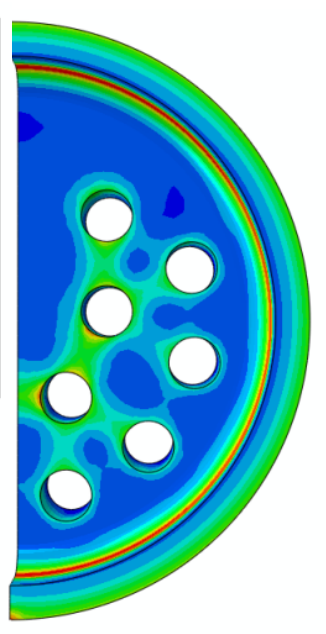
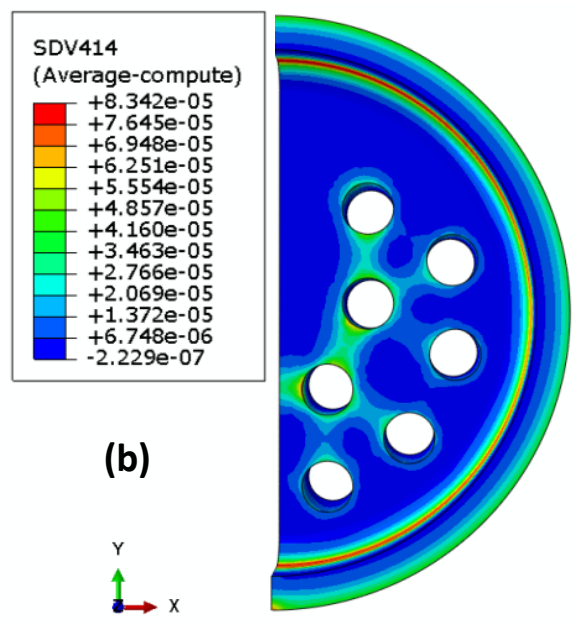

Figure 15 (a) Total strain range and (b) fatigue damage per cycle.

Figure 16 is the Design Fatigue Curve for 316 stainless steel provided in ASME NH which allows to evaluate a number of cycles to fatigue failure $d_{f}^{A S M E}$ against the total strain range $\varepsilon_{t}$ concerning the specific temperature. The total strain range $\varepsilon_{t}$ in Figure 16 is replaced with $\Delta \bar{\varepsilon}_{\text {Total }}$, which is the maximum equivalent strain range including equivalent plastic strain and creep strain increments. The evaluated fatigue damage per cycle based on MUSM is not significant, whereas the fatigue damage on the Design Fatigue Curve is considerable for both the critical elements 15107 and 2. 


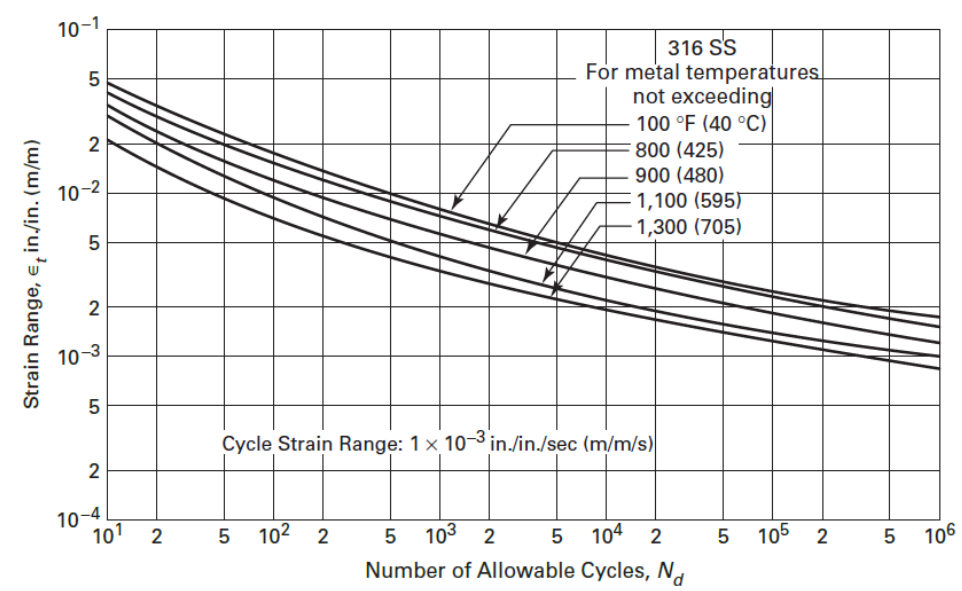

Figure 16 Design fatigue curve $\Delta \varepsilon-N_{d}$ for 316 stainless steel in ASME NH[26].

Figure 17 shows total damage contours for TF, DE, and SEDE methods. Calculated total damages for the dwell period of six months operation are listed in Table 9. Total damage per cycle $d_{\text {Total }}$ is calculated from the summation of both creep damages ( $d_{c}^{1 s t}$ and $d_{c}^{2 n d}$ ) and fatigue damage $d_{f}$.

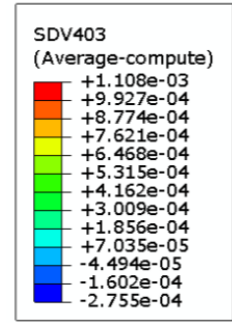

(a) ${ }_{2} \stackrel{x}{2}$

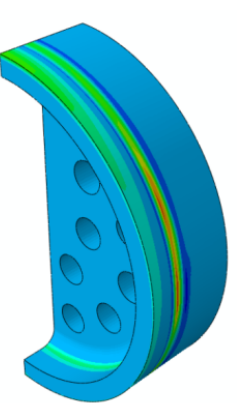

(1)

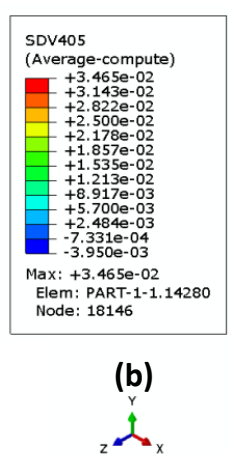

(b)

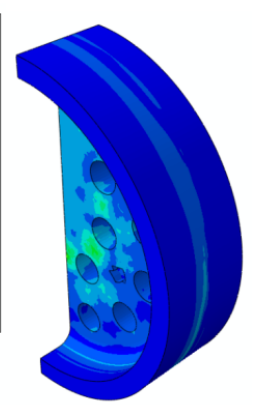

(

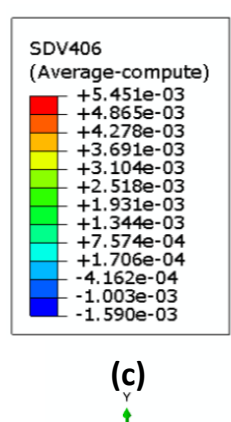

策

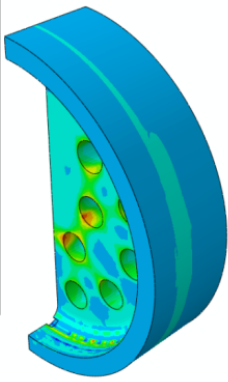

(b) DE model with MDF, and

Figure 17 Total damage per cycle: (a) TF model with

(c) SEDE model with MDFwEN.

Where fatigue damage is evaluated for elements 5670 and 15107 based on MUSM, total damage per

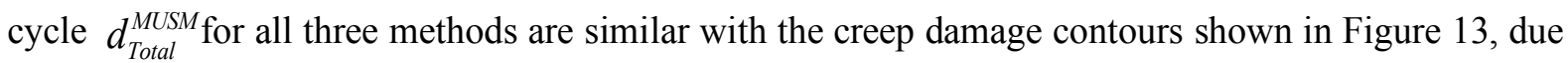
to dominant creep damage accumulation over a cycle. It means that creep damage is the dominant failure mechanism, particularly creep deformation at the $2^{\text {nd }}$ dwell makes considerable impact on the integrity of the tube plate. When the fatigue damage is calculated based on the ASME NH for the same elements, total damage per cycle $d_{\text {Total }}^{A S M E}$ get more influences from the fatigue damage than the creep damage using the SEDE method. However, for the element 2, fatigue damage is the dominant failure mechanism due to the compressive dwell that causes no creep damage. The total damage is significant in the same order of the creep damages. 
Takahashi et al. reported creep-fatigue damage lives for various alloys using the three creep damage evaluation methods [28]. According to the experimental results of Type 316 stainless steel, TF model is likely to predict non-conservative total damage at small strain ranges $\Delta \bar{\varepsilon}_{\text {Total }}<0.7 \%$, but DE model predicts overly conservative total damage for the small total strain ranges. SEDE method shows the best predictability over tested strain range between $0.4 \%$ and $2 \%$, among these three methods.

Table 9 Comparisons of creep-fatigue damage lives for six months operation.

Creep Damage per Cycle

\begin{tabular}{c|c|c|c|c|c|c}
\hline $\begin{array}{c}\text { Element } \\
\text { No. }\end{array}$ & 5670 & \multicolumn{3}{|c|}{15107} & \multicolumn{2}{c}{2} \\
\hline Model & TF $\sigma_{R U P}$ & DE MDF & DE MDFWEN & SEDE MDFwEN & DE MDF & SEDE MDFWEN \\
\hline$d_{c}^{1 s t}$ & $6.11 \mathrm{E}-09$ & $8.8 \mathrm{E}-04$ & $3.8 \mathrm{E}-03$ & $1.7 \mathrm{E}-03$ & 0 & 0 \\
\hline$d_{c}^{2 n d}$ & $5.1 \mathrm{E}-04$ & $9.2 \mathrm{E}-03$ & $2.3 \mathrm{E}-02$ & $2.5 \mathrm{E}-03$ & 0 & 0 \\
\hline
\end{tabular}

\section{Fatigue Damage per Cycle}

\begin{tabular}{c|c|c|c|c|c|c}
\hline Element No. & \multicolumn{2}{|c|}{5670} & \multicolumn{2}{c|}{15107} & \multicolumn{2}{c}{2} \\
\hline$\Delta \bar{\varepsilon}_{\text {Total }}$ & \multicolumn{2}{|c|}{$1.48 \mathrm{E}-03$} & \multicolumn{2}{c|}{$6.8 \mathrm{E}-03$} & \multicolumn{2}{c}{$6.3 \mathrm{E}-03$} \\
\hline Model & MUSM & ASME & MUSM & ASME & MUSM & ASME \\
\hline$d_{f}$ & $6.33 \mathrm{E}-06$ & $<5 \mathrm{E}-05$ & $6.5 \mathrm{E}-05$ & $8.4 \mathrm{E}-03$ & $6.1 \mathrm{E}-05$ & $6.6 \mathrm{E}-03$ \\
\hline
\end{tabular}

\section{Total Damage per Cycle}

\begin{tabular}{c|c|c|c|c|c|c}
\hline $\begin{array}{c}\text { Element } \\
\text { No. }\end{array}$ & 5670 & \multicolumn{3}{|c|}{15107} & \multicolumn{2}{c}{2} \\
\hline Model & TF $\sigma_{\text {RUP }}$ & DE MDF & DE MDFwEN & SEDE MDFwEN & DE MDF & SEDE MDFWEN \\
\hline$d_{\text {Total }}^{\text {MUSM }}$ & $5.2 \mathrm{E}-04$ & 0.01 & 0.026 & 0.0043 & $6.1 \mathrm{E}-05$ & $6.1 \mathrm{E}-05$ \\
\hline$d_{\text {Total }}^{\text {ASME }}$ & $5.6 \mathrm{E}-04$ & 0.018 & 0.035 & 0.0126 & $6.6 \mathrm{E}-03$ & $6.6 \mathrm{E}-03$ \\
\hline$d_{\text {Total }}^{\text {unified }}$ & $9.44 \mathrm{E}-06$ & \multicolumn{3}{|c|}{$1.0 \mathrm{E}-4$} & \multicolumn{2}{c}{$9.67 \mathrm{E}-05$} \\
\hline
\end{tabular}

The two multiaxial ductility factors, MDF and MDF ${ }_{W E N}$, are adopted for DE method in creep damage evaluations; $\mathrm{DE}$ with $\mathrm{MDF}_{\text {WEN }}$ predicts more considerable creep damage than DE with MDF. The results do not conclude which MDF model predicts more acurate creep damage, but it can provide a tendency that affects the creep damage. Although many factors may influence the total damage 
evaluations, the predicted total damages shown in Table 9 present the same tendency as the experimental results.

The unified creep-fatigue equation predicts total damage per cycle $d_{\text {Total }}^{\text {unified }}$ the smallest for elements 5670 and 15107 , among the three methods. For the element 2, although $d_{\text {Total }}^{\text {unified }}$ is more abundant than $d_{\text {Total }}^{M U S M}$, the damage level is small to be negligible. Moreover, the unified creep-fatigue equation was derived based on uniaxial tensile creep rupture data, which might not be suitable to predict total damage life involving either compressive dwell or multiaxial stress state.

With the most conservative approach, the allowable operation cycle of the tube plate evaluated by DE with $M_{\text {DEN }}$ and the Design Fatigue Curve is 20 cycles which is ten years operation according to the creep-fatigue damage envelope for Type 316 stainless steel in ASME NH design codes as shown in Figure 6. It should be mentioned that the service life is only referenced lifetime estimated for this research purpose, but it could be longer if it uses more accurate experimental data.

\section{Conclusions}

Creep-cyclic plasticity of a superheater outlet tube plate subjected to thermo-mechanical load is analysed through the modified LMM eDSCA which is capable of considering non-isothermal creep effects, multiple dwell periods, and dwell relaxation history in stress and strain. Temperature-dependent material properties are employed to calculate more practicable structural behaviour and lifetime prediction. The main results obtained from this work are summarised as below:

In the steady cyclic state, the tube plate has thermal stresses dominated under the thermo-mechanical load, resulting in compressive stresses dominated at the outside of the tube plate in which it is the high temperature side and tensile stresses dominated at tube holed areas in which is the low-temperature side.

In the 1st dwell, maximum creep deformation occurs at the holed area of tube plate due to the larger magnitude of stress, whereas, in the 2nd dwell, maximum creep deformation occurs at the inside fillet edges close to the outside of the tube plate due to larger creep parameter induced by high temperature. Both the locations where the maximum creep deformation occurs show creep ratchetting response by cyclically enhanced creep. The numerical results also demonstrate that the modified LMM eDSCA can produce the effective creep stress history, principal stress history, creep strain increment history over a dwell period. 
The modified LMM eDSCA is aimed to show the capability of evaluating the creep-fatigue damage with the various methods, rather than to conclude which damage model has the best predictability. For creep damage evaluation, Time Fraction (TF), Ductility Exhaustion (DE), Strain Energy Ductility Exhaustion (SEDE) methods were employed with Multiaxial Ductility Factors (MDF). Results show that the outside of the tube plate and the tube holed areas have creep dominated damage mechanism in the steady-state cycle. For fatigue damage assessment, the modified universal slope method (MUSM) and the design fatigue curve provided in ASME NH were considered. Fatigue damage per cycle is considerable when the design fatigue curve is applied, whereas negligible with MUSM. According to the linear damage summation method, the calculated total damage per cycle is decreasing in order of DE, SEDE, and TF which is the same order as creep damage per cycle. The severeness of the total damage is the same as the experimental results reported by Takahashi et al. Multiaxial ductility factor MDFWEN tends to predict more substantial creep damage than MDF provided in R5. The unified creep-fatigue equation evaluates considerably smaller total damage per cycle compared to the linear damage summation method.

Finally, this work shows that the LMM Framework has the vast potential to be applied for the practical creep-fatigue interaction assessment. From the viewpoint of numerical technique, the LMM Framework can be further expanded to other high-temperature problems by implementing other creep constitutive models or hardening models, so that it can aid in solving many complex engineering problems.

\section{Acknowledgements}

The authors gratefully acknowledge the supports from the National Natural Science Foundation of China (51828501), University of Strathclyde and East China University of Science and Technology during the course of this work. The authors also express deep gratitude to Engineering Analysis Service Limited who provides a technical report regarding the creep-fatigue crack initiation assessment of the tube plate. Finally many thanks go to Mr Michael William Spindler of EDF energy for his advices on the creep damage models in this work.

\section{Reference}

1. Sonntag, R.E., et al., Fundamentals of thermodynamics. Vol. 6. 1998: Wiley New York.

2. Jiuyi, L., Q. Caifu, and L. Huifang, Thermal stress analysis on the thick tubesheet with square layout of tubes. International Journal on Interactive Design and Manufacturing (IJIDeM), 2018. 12(1): p. 243-251.

3. Zhang, K., et al., 5 - Boiler design for ultra-supercritical coal power plants, in UltraSupercritical Coal Power Plants, D. Zhang, Editor. 2013, Woodhead Publishing. p. 104-130.

4. Wang, W., Analysis of multi-axial creep-fatigue damage on an outer cylinder of a $1000 \mathrm{MW}$ supercritical steam turbine. Journal of Engineering for Gas Turbines and Power, 2014. 136(11): p. 112504. 
5. Wang, W., Numerical Analysis of Fatigue Life Improvement by Optimizing the Startup Phase for a 1000 MW Supercritical Steam Turbine Inner Casing. Journal of Engineering for Gas Turbines and Power, 2015. 137(4): p. 042601.

6. Mao, J., et al. Multiaxial creep-fatigue life prediction on the rotor of a $1000 \mathrm{MW}$ supercritical steam turbine. in ASME Turbo Expo 2012: Turbine Technical Conference and Exposition. 2012. American Society of Mechanical Engineers.

7. $\mathrm{Xu}, \mathrm{H} ., \mathrm{S} .-\mathrm{H}$. Zheng, and K. Maile, Research on the fatigue-creep rupture of fastening bolts of ultra-supercritical steam turbine cylinder case. Proceedings-Chinese society of electrical engineering, 2007. 27(32): p. 63.

8. Barbera, D., H. Chen, and W. Luan. Direct Method on Creep Fatigue Damage Assessment Considering Full Creep-Cyclic Plasticity Interaction. in ASME 2017 Pressure Vessels and Piping Conference. 2017. American Society of Mechanical Engineers.

9. Cho, N.-K. and H. Chen. Investigation of structural creep strain recovery and its impact on structural integrity. in 24th International Conference on Structural Mechanics in Reactor Technology. 2017.

10. Cho, N.-K., et al., Enhanced fatigue damage under cyclic thermo-mechanical loading at high temperature by structural creep recovery mechanism. International Journal of Fatigue, 2018.

11. Ainsworth, R., R5: Assessment procedure for the high temperature response of structures. British energy generation Ltd, 2003. 3.

12. ASME, ASME Boiler and Pressure Vessel Code: An International Code, Division 1-Subsection NH. The American Society of Mechanical Engineers, New York, 2013.

13. Chen, H. and A.R. Ponter, Structural integrity assessment of superheater outlet penetration tubeplate. International Journal of Pressure Vessels and Piping, 2009. 86(7): p. 412-419.

14. Chen, H., J. Ure, and D. Tipping, Calculation of a lower bound ratchet limit part 1-Theory, numerical implementation and verification. European Journal of Mechanics-A/Solids, 2013. 37: p. 361-368.

15. Chen, H., Lower and upper bound shakedown analysis of structures with temperaturedependent yield stress. Journal of Pressure Vessel Technology, 2010. 132(1): p. 011202.

16. Chen, H.F., M.J. Engelhardt, and A.R.S. Ponter, Linear matching method for creep rupture assessment. International Journal of Pressure Vessels and Piping, 2003. 80(4): p. 213-220.

17. Lytwyn, M., H. Chen, and M. Martin, Comparison of the Linear Matching Method to RollsRoyce's Hierarchical Finite Element Framework for ratchet limit analysis. International Journal of Pressure Vessels and Piping, 2015. 125: p. 13-22.

18. Chen, H., W. Chen, and J. Ure, A direct method on the evaluation of cyclic steady state of structures with creep effect. Journal of Pressure Vessel Technology, 2014. 136(6): p. 061404.

19. Spindler, M.W., An improved method for calculation of creep damage during creep-fatigue cycling. Materials Science and Technology, 2013. 23(12): p. 1461-1470.

20. Wen, J.-F., et al., Effects of stress level and stress state on creep ductility: evaluation of different models. Journal of Materials Science \& Technology, 2016. 32(8): p. 695-704.

21. Spindler, M., ECCC Data Sheets 2014. UK: ETD Ltd, 2014. 47(2).

22. Afcen, D., Construction Rules for Mechanical Components of PWR Nuclear Islands RCC-M. Addendum: AFCEN, 1985.

23. Spindler, M., The multiaxial creep ductility of austenitic stainless steels. Fatigue \& fracture of engineering materials \& structures, 2004. 27(4): p. 273-281.

24. Spindler, M., An Improved Method to Calculate the Creep-Fatigue Endurance of Type 316H Stainless Steel. 2006. 1673-1682.

25. Wang, R.-Z., et al., A modified strain energy density exhaustion model for creep-fatigue life prediction. International Journal of Fatigue, 2016. 90: p. 12-22.

26. NH-Boiler, A. and P.V. Code, Section III, Division 1, Subsection NH, Class 1 Components in Elevated Temperature Service. American Society of Mechanical Engineers, New York, NY, 2009. 
27. Huang, J.-Y., et al., High-cycle fatigue behavior of type 316L stainless steel. Materials transactions, 2006. 47(2): p. 409-417.

28. Takahashi, Y., B. Dogan, and D. Gandy. Systematic evaluation of creep-fatigue life prediction methods for various alloys. in ASME 2009 Pressure Vessels and Piping Conference. 2009. American Society of Mechanical Engineers. 